\title{
Nusselt number analysis from a battery pack cooled by different fluids and multiple back-propagation modelling using feed-forward networks
}

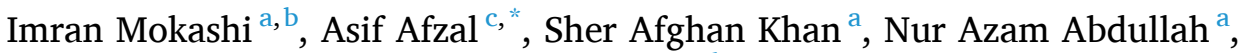 \\ Muhammad Hanafi Bin Azami ${ }^{\text {a }}$, R.D. Jilte ${ }^{\mathrm{d}}$, Olusegun David Samuel ${ }^{\mathrm{e}}$ \\ ${ }^{a}$ Department of Mechanical Engineering, International Islamic University Malaysia, Kuala Lumpur, Malaysia \\ ${ }^{\mathrm{b}}$ Department of Mechanical Engineering, Bearys Institute of Technology, (Affiliated to Visvesvaraya Technological University), Mangaluru, Karnataka, India \\ ${ }^{\mathrm{c}}$ Department of Mechanical Engineering, P. A. College of Engineering (Affiliated to Visvesvaraya Technological University, Belagavi), Mangaluru, India \\ ${ }^{\mathrm{d}}$ Department of Mechanical Engineering, Lovely Professional University, Punjab, 144411, India \\ ${ }^{\mathrm{e}}$ Department of Mechanical Engineering, Federal University of Petroleum Resources, Effurun, Delta State, PMB 1221, Nigeria
}

\section{A R T I C L E I N F O}

\section{Keywords:}

Battery pack

Coolants

Prandtl number

Nusselt number

Reynolds number

Conductivity ratio

\begin{abstract}
A B S T R A C T
In this article, analysis of average Nusselt number $\left(N u_{a v g}\right)$, which indicates the heat removal from the battery pack cooled by flowing fluid is carried out considering coupled heat transfer condition at the pack and coolant interface. Five categories of coolant, mainly gases, common oils, thermal oils, nanofluids, and liquid metals, are selected. In each coolant category, five fluids (having different Prandtl number Pr) are selected and passed over the Li-ion battery pack. The analysis is made for different conductivity ratio $(\mathrm{Cr})$, heat generation term $\left(Q_{g e n}\right)$, Reynolds number $(R e)$, and $P r$. Pr varying in the range 0.0208-511.5 (25 coolants) and $\mathrm{Cr}$ for each category of coolant having its own upper and lower limit are used to analyze the heat removed from the battery pack. Using single feed-forward network and integrating two feed-forward networks having multi-layers with backpropagation is employed for artificial neural network (ANN) modelling. In this modelling, the concept of the main network and space network is devised for multiple back propagation (MBP). The numerical analysis revealed that the temperature distribution in battery and fluid is greatly affected by increasing $\mathrm{Cr}$. The maximum temperature located close to the upper edge of battery is found to get reduced significantly with the increase of $\mathrm{Cr}$, but upto a certain limit above which reduction is marginal. The analysis carried out reveals that $\mathrm{Cr}$ and $Q_{g e n}$ have no role in improving $N u_{a v g}$ while $P r$ and $R e$ vary it significantly in each step. Moreover, $N u_{a v g}$ is found to increase with $R e$ continuously irrespective of any $\mathrm{Cr}$ and $Q_{g e n}$. While, for oils with an increase in $\operatorname{Pr}$ and $R e, N u_{a v g}$ was found to reduce significantly. Nanofluids are found to be more effective in improving heat transfer from the battery pack when cooled by flowing nano-coolants over it. The MBP networks proposed are successfully trained, and hence they can be used for prediction of $N u_{a v g}$.
\end{abstract}

\section{Introduction}

The increasing price of oil and environmental concerns has lead the automotive industry to develop appropriate alternatives such as HEV (hybrid electric vehicles) in place of oil-based engines. A recent survey by the energy department of US has shown that only $15 \%$ of the fuel is used for functioning of the vehicle and its components in conventional IC engines, and more than $40 \%$ of the fuel is wasted as heat through emissions [1]. The hybrid vehicles use technology designed to decrease the use of gasoline and diesel. The HEVs are usually operated by lithium-ion (Li-ion), nickel-zinc, and lead-acid batteries to decrease the use of gasoline and diesel fuel. Among these, Li-ion battery (LIB) can be considered as the most important option owing to high energy density, high stability, and slow discharge rates. Nevertheless, the issues related to the thermal safety of LIB cannot be neglected [2-5]. The heat generation rate in these battery cells during charging is on average of $2-20$ $\mathrm{W}$ per cell with a peak of up to $50 \mathrm{~W}$, thus increasing the temperature of the battery cells [6]. Therefore cooling of these battery cells becomes necessary. Also, the LIBs have to convert more chemical energy into heat energy by a series of exothermic reactions during abusive conditions and operations at elevated ambient temperatures. This leads to more heat buildup in the battery, producing a substantial deterioration and the condition of fire, burning, and explosion hazards [7-9]. Hence, BTMS

\footnotetext{
* Corresponding author.

E-mail address: asif.afzal86@gmail.com (A. Afzal).
} 


\begin{tabular}{|c|c|c|c|}
\hline \multicolumn{2}{|c|}{ Nomenclature } & $\mathrm{Nu}$ avg & Average Nusselt number \\
\hline$A_{r}$ & Aspect ratio & $v$ & Velocity along the transverse direction $\mathrm{m} / \mathrm{s}$ \\
\hline BTMS & Battery thermal management system & $\mathrm{V}$ & Non-dimensional velocity along the transverse direction \\
\hline $\mathrm{Cr}$ & Conductivity ratio & $w$ & Half-width $\mathrm{m}$ \\
\hline CFD & Computational fluid dynamics & $W_{s}$ & Non-dimensional width \\
\hline$D O D$ & Depth of discharge & \multirow{2}{*}{\multicolumn{2}{|c|}{ Greek symbols }} \\
\hline HEV & Hybrid electric vehicle & & \\
\hline LIB & Lithium-ion battery & $\alpha$ & Thermal diffusivity of fluid $\mathrm{m}^{2} / \mathrm{s}$ \\
\hline$M B P$ & Multiple back propagation & $\nu$ & Kinematic viscosity of the fluid $\mathrm{m}^{2} / \mathrm{s}$ \\
\hline$L$ & Length of the battery cell $m$ & $\rho$ & Density of fluid $\mathrm{kg} / \mathrm{m}^{3}$ \\
\hline$k$ & Thermal conductivity $\mathrm{W} / \mathrm{m}^{2} k$ & $\mu$ & Dynamic viscosity $\mathrm{Ns} / \mathrm{m}$ \\
\hline$q^{\prime \prime \prime}$ & Volumetric heat generation $\mathrm{W} / \mathrm{m}^{3}$ & \multicolumn{2}{|c|}{ Subscripts } \\
\hline$Q_{\text {gen }}$ & Dimensionless volumetric heat generation & $c$ & center \\
\hline $\operatorname{Pr}$ & Prandtl number & $f$ & fluid domain \\
\hline Re & Reynolds number & $b$ & battery \\
\hline$T^{*}$ & Temperature ${ }^{\circ} \mathrm{C}$ & $\infty$ & free stream \\
\hline$T$ & Non-dimensional temperature & $\max$ & maximum \\
\hline$u$ & Velocity along the axial direction $\mathrm{m} / \mathrm{s}$ & men & solid \\
\hline$U$ & Non-dimensional velocity along the axial direction & & \\
\hline
\end{tabular}

(battery thermal management system) plays a very significant role in the safe operation of HEVs. BTMS using air and water coolants are common in which the experimental and numerical analysis are carried.

\subsection{Air cooled BTMS}

The following research gives the overview of recent work related to thermal management of the battery system using forced convection air cooling. Wang et al. [10] carried out an experimental investigation to study the thermal behavior of an air-cooled LIB. They used reciprocating air-flow cooling method for uniform temperature distribution and found reduction of temperature fluctuation in each of the battery cells and found a desired reverse timing of about $50 \%$ DOD (depth of discharge) at $3 \mathrm{C}$ discharge rate by considering battery temperature limit and cooling effects. In another study, Wang et al. [11] created a three-dimensional CFD (computational fluid dynamics) model to analyze the factors affecting the cooling performance of forced convection air cooling on different cell arrangements of the battery packs. The temperature distribution uniformity problem was also investigated by installing the fans in different locations of the battery module. They found the best cooling performance for the cubic arrangement of the battery module with the location of the fan on the top of the battery. They also found the optimized channel spacing for the maximum performance of the battery. $\mathrm{Na}$ et al. [12] proposed a novel 3D CFD model of the BTMS to improve the temperature uniformity in between the cells, minimize the maximum temperature and minimize the average temperature difference using reverse layered airflow system. They compared their results with a unidirectional system and found a remarkable improvement in the proposed model.

Lu et al. [13] designed a 3D model of the staggered battery pack to study the effect of spacing between the channels and airflow rate on the thermal performance of the battery. They found that the maximum cooling efficiency can be achieved when the airflow inlet or outlet is kept at the top of the battery. They also found optimum channel size to minimize the maximum temperature in the battery. Fan et al. [14] analyzed the thermal behavior of prismatic li-ion battery cells for an aggressive driving profile. They created a 3D CFD model and carried the transient thermal analysis. Air as a cooling medium was passed through the evenly spaced channels. They found a decrease in temperature with an increase in flow rate and a decrease in spacing. They also found that temperature gradients are affected mainly by the direction of airflow to get a uniform temperature distribution, the flow direction should also be taken into consideration. Giuliano et al. [15], designed a BTMS with air as a cooling medium in a metal-foam based heat exchanger plates. They found an airflow rate of $1100 \mathrm{mls}^{-1}$ per cell to restrict temperature rise of about $10{ }^{\circ} \mathrm{C}$ for both the charging and discharging cycles. They also concluded that air cooling systems are the most effective and proficient system for automotive battery packs. Zhu et al. [16] created an electrochemical-thermal model of LIB packs using forced convection air-cooling system. It utilizes the reciprocating airflow pattern where the flow was periodically reversed to decrease the temperature gradients, thus restricting the hazardous phenomena of the high-temperature difference of the battery cells caused in traditional one-directional air-cooling system. Saw et al. [17] conducted a steady-state conjugate analysis using air as a cooling medium for battery performance. A correlation was also developed between the Nusselt number and the Reynolds number. The correlation was verified by conducting experimental analysis at different discharge rates.

Air cooled system based BTMS is numerically analyzed for asymmetrical and symmetrical arrangements of batteries with different spacings between them [18]. Modified air flow path like wedge shaped runner is also used and their structure is optimized [19]. Realistic thermal models for air cooled batteries are used for heat dissipation study [20,21]. Panchal et al. [22] analyzed a prismatic Li-ion battery system and measured the rate of heat generation for different discharge rates and operating conditions. They found an increase in heat generation rate with an increase in discharge rates and current. Later, they developed an ANN (artificial neural network) model and predicted other results. They also found the surface temperature distribution of a superior lithium polymer battery system for different discharge rates and found an increase in the surface temperature distribution with an increase in discharge rates [23].

\subsection{Liquid cooled BTMS}

BTMS becomes necessary when the battery is operated at high rates of charging and discharging and ultrahigh ambient temperatures [24, 25]. It can be seen that the BTMS methods can be categorized into various types like liquid cooling, air cooling and PCM (phase change material) cooling-based system [26,27]. As compared to air cooling, liquid cooling needs to include more weight which increases the design complexity. In addition, the liquid coolant leakage issue and the significant expense additionally limit it enormous scale in EVs [28].

Chen et al. [29] compared the different cooling methods used in 
thermal management of Li-ion battery pack experimentally. Four different methods such as air cooling, direct liquid cooling, indirect liquid cooling and cooling by use of fins are demonstrated clearly in this investigation. The results of this study show that the use of fins on battery cell may increase the weight of the battery system, air cooling may consume more amount of energy to produce same cooling effects and liquid cooling proves to be more effective in terms of maximum temperature control and distribution. Qian et al. [30] suggested a 3D numerical model for thermal management of battery system subjected to liquid cooling method with minichannel plates. The parameters like flow channel width, flow rate and number of channels on the thermal behavior of battery pack were examined in detail. The outcomes of this numerical investigation says that use of minichannel cold plate improves the overall cooling efficiency of the battery module as well as the uniformity of temperature distribution in the battery cell is improved to a greater extent. Chalise et al. [31] carried a conjugate heat transfer study of Li-ion battery pack subjected to forced convection with an analytical approach. Considering steady state heat transfer, uniform heat generation, and external flow of coolant over the pack, temperature variations were studied. For few flow velocities $(0.5-5 \mathrm{~mm} / \mathrm{s})$ and discharge rates (1-5 C rates) the heat transfer study was carried out. The results obtained using analytical iterative method for the conjugate analysis shows that the proposed analytical method is more effective in determining the thermal and electrochemical performance of the battery pack.

\subsection{PCM cooled BTMS}

Towards PCM cooling framework, the latent heat recovery and the coordination of PCM framework is also used for enhancement for the BTMS application [32-34]. Situa et al. [35] carried a numerical heat transfer analysis of rectangular battery module under forced convection condition. The proposed thermal model of battery system in this study made use of PCM plate for optimal cooling. The results of this simulation study shows an excellent improvement in the temperature distribution in a battery module when meshed PCM is used. The results also conclude that the use of cooling plate reduces the maximum temperature and temperature difference in battery module to great extent which is helpful in optimal design of the whole battery system. Xie et al. [36] proposed a coupled air and phase change material thermal cooling system for Li-ion batteries used in the power trains. The investigation is done both numerically and experimentally. The effects of PCM liquid fraction and flow rate of air on battery thermal performance were determined. The outcomes of this study suggests that the combined cooling method is far better than air cooling method but air cooling method is found to be effective when the flow rate is around $300 \mathrm{~m}^{3} / \mathrm{h}$ and integrated cooling method is more effective when the flow rate is $100 \mathrm{~m}^{3} / \mathrm{h}$ finally it is concluded that the coupled phase change material and air cooling method proves to be good in controlling the maximum temperature of battery module.

\subsection{Motivation and objectives}

From the literature review, it is very much clear that most of the research is either experimental or numerical (using commercial software) on only the solid portion of Li-ion battery cells to investigate the thermal behavior during the charging/discharging process for different boundary conditions. Some researchers have also made a detailed investigation considering the cooling arrangement of BTMS for unidirectional and reciprocating flow arrangement. Air, water, and PCM are used as an important cooling medium for LIBs. But except for the work of Saw et al. [17] and Chalise et al. [31], none of the work is on conjugate heat transfer considering the coupling of the conduction in the battery and the coolant flowing over it. Despite the fact that Saw et al. [17] have considered a coupled heat transfer condition, their study was using Ansys Fluent and air as coolant. Chalise et al. [31] also performed conjugate analysis, but used only dielectric oil and water as the coolant for the temperature variation analysis. Their study does not give details about Nusselt number analysis for different coolants. Additionally in detailed Nusselt number analysis considering either conjugate conditions and non-conjugate condition is also not seen. Neural network modelling of Nusselt number is battery thermal systems is also not found in the previous works with the exception of Panchal et al. [22]. In this article, efforts are made to address the above issues by considering realistic conjugate heat transfer boundary conditions, which involves the coupling of conduction of the battery cells with convection of the coolants at the solid-fluid interface. Use of different categories of coolants like nanofluids, gases, liquid metal coolants, etc. is also new. Five categories of coolants are considered to analyze the average Nusselt number $\left(N u_{a v g}\right)$ during the coolant flow over the battery pack. $N u_{a v g}$ using three back propagation models is reported for the first time.

\section{Mathematical formulation}

The conjugate heat transfer (CHT) [37] problem used for the solution of cooling of the Li-ion battery pack with fluid as a coolant is shown in Fig. 1 (a). Fig. 1 (a) also shows the battery cell that repeats itself in the stack of cells. It can be seen that the performance of the cooling system is not dependent on the number of batteries in a battery module. Hence only two battery cells are considered for the analysis, and in between these cells, the fluid flows and carries away the heat. The individual prismatic battery cell may have cylindrical or rectangular cross-sections. It is assumed rectangular in this paper, and it dissipates the volumetrically generated heat to the surrounding air, as shown in Fig. 1 (b). Geometric and thermal symmetries about the vertical axis and computational economy were considered, only half of the physical domain is taken as the computational domain (Fig. $1 \mathrm{c}-\mathrm{d}$ ). In this problem, the temperature distribution within the battery cell is determined as a function of operating parameters of the cell [volumetric heat generation $(q$ ','), conductivity ratio $(\mathrm{Cr})]$ and the properties and parameters related to the coolant [Reynolds number $(R e)$, Prandtl number $(P r)]$. The present work is a CHT problem that involves the coupling of conduction heat transfer in the solid cell with that of convection heat transfer in the fluid cells, and it is comparatively difficult to solve due to the continuous interaction of the solid with the fluid. Therefore an iterative finite volume method (FVM) is used for the analysis. The cell dimensions vary between from $0.1 \mathrm{~mm}$ to $30 \mathrm{~mm}$ in thickness, $50 \mathrm{~mm}-550 \mathrm{~mm}$ in length and $20 \mathrm{~mm}-200 \mathrm{~mm}$ in width. As the thickness of each layer in the cell of the battery is negligibly small compared to its other dimensions [38,39] and simulating the complex electrochemical reactions in 3D is computationally expensive So a two-dimensional model is chosen for the study without sacrificing the accuracy of the results [31,40].

Now to transform the physical model considered for the analysis to a mathematical model, certain assumptions are made which are stated below:

(i) The heat generation is considered to be uniform [41] varying from $6.855 \times 10^{3}$ to $2 \times 10^{6} \mathrm{~W} \mathrm{~m}^{-3}$ [42]

(ii) The flow is assumed to be transient $[43,44]$, laminar $[45,46]$ and two dimensional [40].

(iii) Flow is assumed to be incompressible

(iv) Viscous dissipation is neglected as the flow is laminar [31].

(v) The thermal conductivity of the unit cell is temperature independent and ranges from 0.02 to $30 \mathrm{~W} \mathrm{mK}^{-1}[40,42]$.

(vi) The fluid is presumed to have persistent thermo-physical properties.

The energy conservation in the battery is governed by the following equation:

$\left(k_{s} \nabla^{2} T\right)+q^{\prime \prime \prime}=\rho c \frac{\partial T}{\partial t}$ 


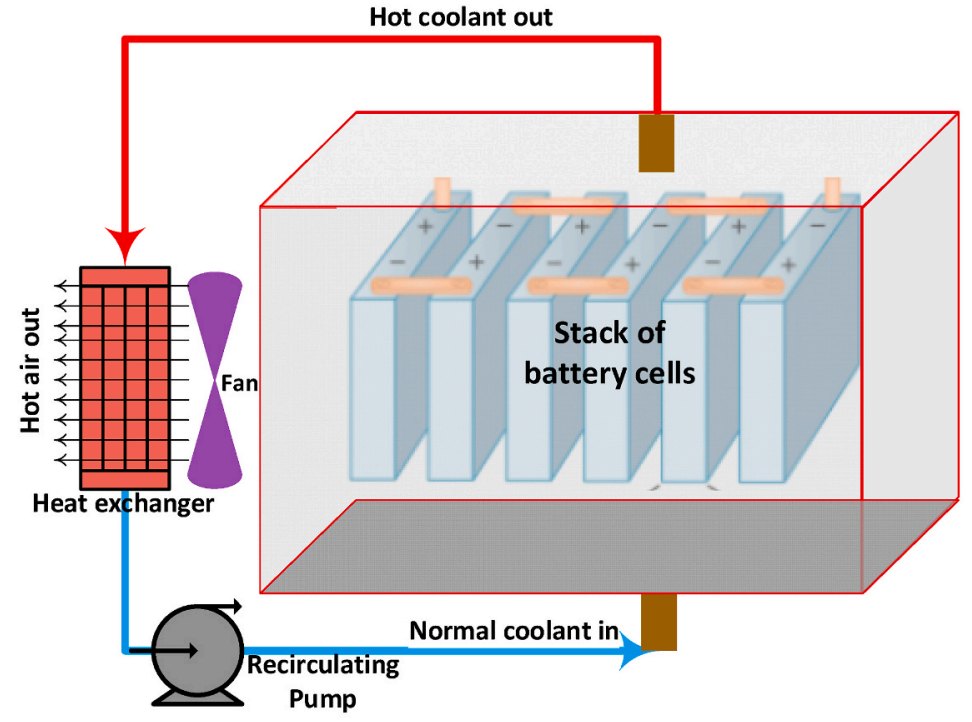

(a) arrangement of the stack of battery cells placed parallelly and cooled by the flow of coolant that is circulated by pump along with a heat exchanger and fan where the coolant gives off the heat to surrounding

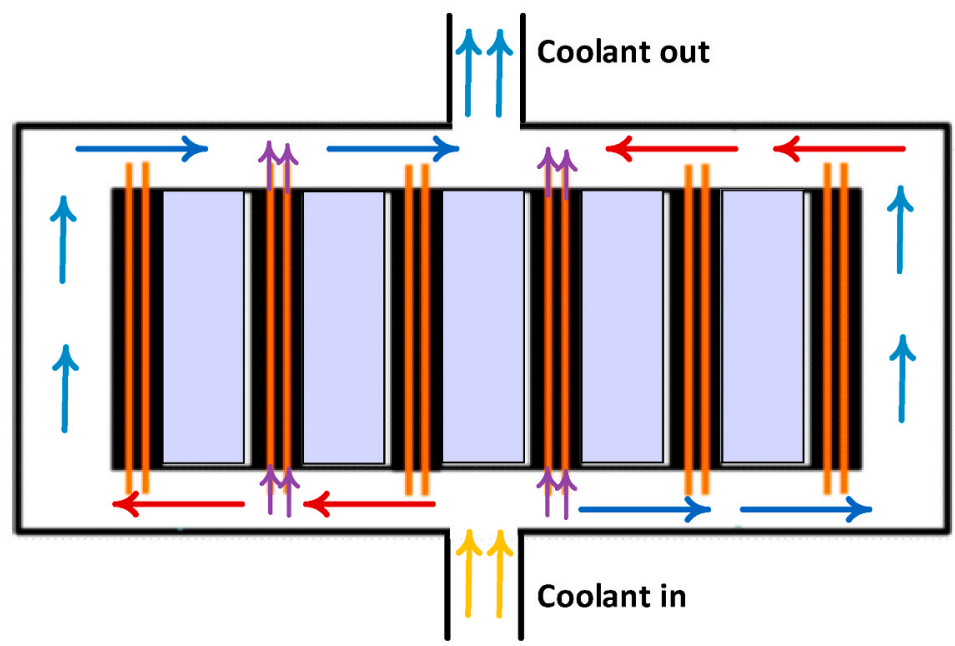

(b) battery cells cooling using a coolant flowing in at the bottom and exiting from the top manifold

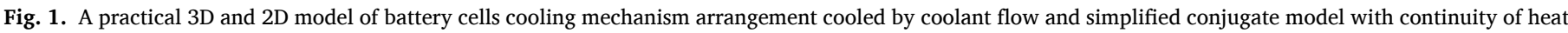
flux at the interface.

Where $q_{g e n}^{\prime \prime \prime}$ is the volumetric heat generation term.

The governing equations affecting the heat transfer and fluid flow, namely, the continuity equation, Navier-Stokes equations, and energy equation, are given as [47].

$\nabla \cdot u^{*}=0$

$\frac{\partial u^{*}}{\partial t}\left(u^{*} \cdot \nabla u^{*}\right)=-\frac{1}{\rho} \nabla p+\mu \nabla^{2} u^{*}$

$\frac{\partial T^{*}}{\partial t}+u \cdot \nabla T^{*}=\frac{\alpha}{\rho c} \nabla^{2} T^{*}$
Where $\rho$ is the density of the fluid, $c$ is the specific heat, and $T$ is the temperature. These equations are normalized using the non-dimensional parameters defined below

$Q_{g e n}=\frac{q_{g e n}^{\prime \prime \prime} w_{s}^{2}}{k_{s}\left(T_{o}-T_{\infty}\right)}, M=4 A_{r}^{2}, T=\frac{T^{*}-T_{\infty}}{T_{0}-T_{\infty}}$

$X=\frac{x}{L}, \quad U=\frac{u^{*}}{u_{\infty}}, \quad V=\frac{v^{*}}{u_{\infty}}, \quad P=\frac{p}{\rho u_{\infty}^{2}}, A_{r}=\frac{L}{2 w_{b}}$

$Y_{s}=\frac{y_{s}}{w_{s}}, Y_{f}=\frac{y_{f}}{L}, W_{f}=\frac{w_{f}}{L}, C r=\frac{k_{f}}{k_{s}}, R e=\frac{u_{\infty} L}{\nu}$, 


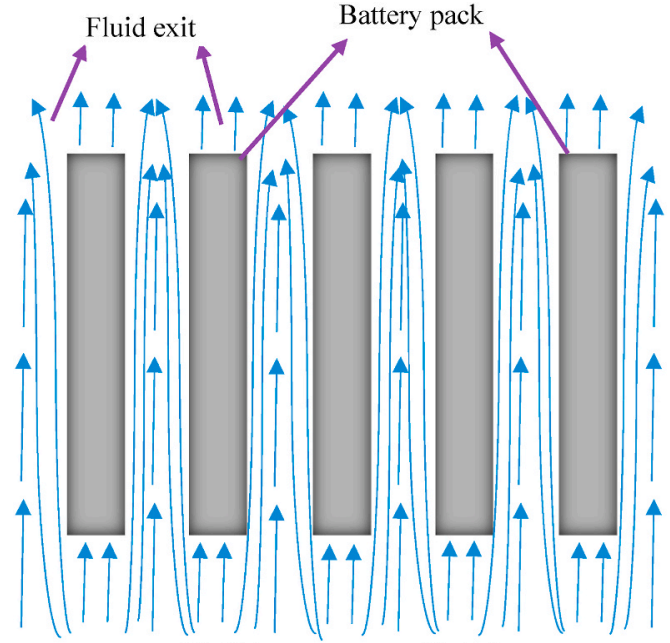

Fluid in
Fluid in

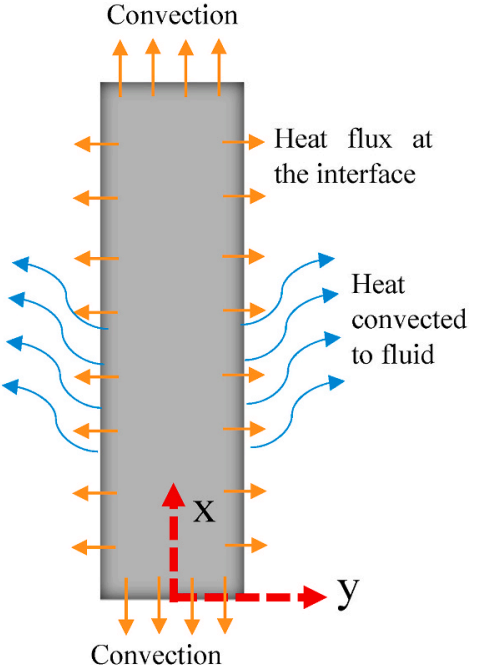

Convection

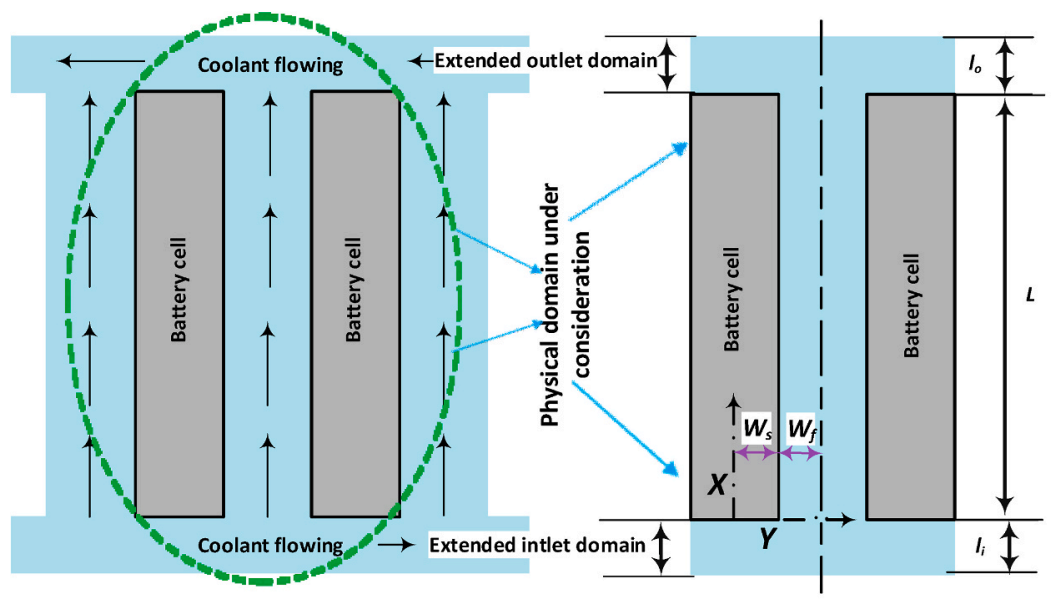

(e) Computational domain of the conjugate problem

Fig. 1. (continued).

$\operatorname{Pr}=\frac{\nu}{\alpha}, \quad \tau=\frac{u t}{L}$

The non-dimensional variables appearing in Equation (5) are: $Q_{g e n}$ is heat generation inside the battery, $M$ is a constant appearing due to Aspect ratio $A_{r}$ of the battery, $T$ is a non-dimensional temperature. The other non-dimensional terms are: vertical axis $X$, velocity along $X$ direction is $U$, velocity along $Y$ direction is $V$, and pressure $P$. $Y_{S}$ is for battery (solid) $Y$ direction, $Y_{f}$ is for fluid $Y$ axis, $W_{f}$ is fluid domain or channel width, $\mathrm{Cr}$ is the conductivity ratio appearing as ratio of thermal conductivity of fluid and battery. Re is the Reynolds number, Pr is coolant Prandtl number, and $\tau$ is time.

The above gives rise to the non-dimensional set of governing equations as

$\frac{\partial T_{b}}{\partial \tau}=\frac{\partial^{2} T_{b}}{\partial X^{2}}+M \frac{\partial^{2} T_{b}}{\partial Y_{b}^{2}}+M Q_{g e n}$ $\nabla U=0$

$\frac{\partial U}{\partial \tau}+U \nabla U=-\nabla P+\frac{1}{R e} \nabla^{2} U$

$\frac{\partial T_{f}}{\partial \tau}+U \nabla T_{f}=\frac{1}{\operatorname{RePr}} \nabla^{2} T_{f}$

To solve the above set of equations in the cell and in the fluid domain, boundary conditions has to be used. The most meaningful boundary conditions are given below. Since the incoming fluid is assumed to enter at the free stream temperature $\left(T_{\infty}\right)$ and uniform velocity $U_{\infty}$ at the inlet, for $\tau>0$ the boundary condition at the inlet is given by:

$X=0 ; 0 \leq Y_{f} \leq 1, U=1, V=0, T_{f}=0$

On the left side, the thermal symmetry boundary condition exists. Hence 
$Y_{b}=0 ; 0 \leq X \leq 1, \frac{\partial T_{b}}{\partial X}=0$

At the interface, continuity of temperature boundary condition is used.

$Y_{b}=1 ; 0 \leq X \leq 1, T_{b}=T_{f}$

At the top of the domain, heat transfer is assumed to be by convection as at the exit of the cell cathode and anode current collector are present [48-50]. Therefore

$X=1 ; 0 \leq Y_{b} \leq 1,-k_{b} \frac{\partial T_{b}}{\partial Y_{b}}=h\left(T^{*}-T_{\infty}\right)$

At the bottom, the coolant hits the base of the battery pack and loses heat by convection hence at

$X=0 ; 0 \leq Y_{b} \leq 1, k_{b} \frac{\partial T_{b}}{\partial Y_{b}}=h\left(T^{*}-T_{\infty}\right)$

The computational domain, shown in Fig. 1 (e), is extended in axial $(X)$ direction in order that the heat transfer and fluid flow parameters are captured completely. Its height is chosen as li at the inlet and lo at the exit, based on a few preliminary studies performed. This was done to enforce physically meaningful additional boundary conditions given as

$Y_{f}=0 ; 0 \leq X \leq 1 \frac{\partial T_{f}}{\partial Y_{f}}=\frac{L}{W_{b}} \frac{1}{C r} \frac{\partial T_{b}}{\partial Y_{b}}, U=0, V=0$

$Y_{f}=W_{f} ; 0 \leq X \leq 1, \frac{\partial T_{f}}{\partial Y_{f}}=0, V=0, \frac{\partial U}{\partial Y_{f}}=0$

$X=1 ; 0 \leq Y_{f} \leq W_{f}, \frac{\partial T_{f}}{\partial X}=0$

The coolant average Nusselt number $\left(N u_{\text {avg }}\right)$ is calculated using Equation (12). Using Newton's law of cooling at the cell and coolant interface we get:

$-\left.k \frac{\partial T^{*}}{\partial Y}\right|_{y_{b}=w_{b}}=h\left(T_{y_{b}=w_{b}}^{*}-T_{\infty}^{*}\right)$

Where, $T_{\infty}$ is the temperature of the fluid domain outside the boundary layer and $T_{b, s}$ is the cell surface temperature. Using appropriate dimensionless parameters, the local $N u_{\mathrm{x}}$ is obtained, which is integrated over the pack surface length to get $N u_{\text {avg }}$.

$N u_{x}=-\left.\frac{1}{\left(T_{Y_{b}=W_{b}}-T_{\infty}\right)} \frac{\partial T}{\partial Y}\right|_{Y_{b}=W_{b}}$

$N u_{\text {avg }}=-\left.\int_{0}^{1} \frac{1}{\left(T_{Y_{b}=W_{b}}-T_{\infty}\right)} \frac{\partial T}{\partial Y}\right|_{Y_{b}=W_{b}} d X$

\subsection{Method of solution and validation}

The normalized governing equations [Eqs. (6)-(9)] are coupled nonlinear partial differential equations. Hence to solve these equations, a suitable numerical solution has to be used. In this paper, Finite volume method (FVM) is used to solve the equation. The solution of the equations is obtained in two stages. In the first stage, all the governing equations are transformed into finite difference equations by applying the finite volume method. In the second stage, the resulting algebraic equations are solved using the boundary conditions. Convergence criteria of error less then $1 * 10^{-6}$ is imposed on temperature, velocity, and pressure output. To discretize the equation in space in solid domain, second order central difference scheme is used. Under relaxation (relaxation parameter $=0.5$ ) is imposed on all the parameters of interest to get the convergence. As the equations of continuity and momentum are coupled in nature, these are solved simultaneously. The temperature distribution in the solid and fluid domain is obtained by the coupling conduction equation with the energy equation using the conjugate boundary condition. The pressure term in the continuity and momentum equation is obtained using the SIMPLE algorithm, for this staggered grids are used. The time-dependent $U^{*}$ and $V^{*}$ velocity components that arrive while using the SIMPLE algorithm are solved using the second order accurate alternating direction implicit (ADI) scheme. The resulting tridiagonal system of linear equations are solved using the Thomas algorithm. After calculating $U^{*}$ and $V^{*}$, the pressure correction $P^{\prime}$ equation obtained employing the continuity equation is solved by the successive over-relaxation (SOR) method. The corrected pressure $P^{\prime}$ calculated to satisfy the continuity equation is further used to correct the guessed $U^{*}$, $V^{*}$, and $P^{*}$. Similarly, the time dependent temperature values at the solid domain and fluid domain are obtained by simultaneously solving conduction and energy equation using conjugate boundary conditions applying the ADI scheme and Thomas algorithm.

\subsection{FVM code validation and grid sensitivity test}

The present analysis is performed employing FVM based code written in C language. Therefore the validation of the present method is necessary before the discussion of results. Many kinds of analyses are seen in past researches in which numerical, experimental, and analytical methods are adopted for the thermal study of the battery system. Among them, all the types of work are selected for the validation of the current analysis. Richter et al. [51] performed an experimental investigation on thermal conductivity and temperature profiles in the lateral direction of the battery. Chalise et al. [31] used finite element method (FEM) and analytical method to solve the conjugate problem in battery system. Both these works are found to be useful for validation of this work; their work guides in temperature profile along the axial and lateral direction. Chalise et al. [31] is close to present work as they have considered the conjugate condition in battery system analysis. Richter et al. [51] performed experimental analysis of temperature profiles in a single battery pack. In Fig. 2 (a) and (b), the results obtained from the FVM code and the previous works are presented at different heat generation rates of the battery pack in non-dimensional form, as mentioned previously. The results of Richter et al. [51] and Chalise et al. [31] are found to be in-line with each other. Though very slight variation can be seen due to different techniques adopted, the validation of the FVM code is established at this stage. The experimental work [51] reported temperature profiles for discharge of $6 \mathrm{C}$ and $2 \mathrm{C}$ along the transverse direction of battery cell i.e. along the width starting from the center to the lateral surface. The temperature reduces from maximum to minimum along the width. In the present analysis the equivalent non-dimensional heat generation $Q_{\text {gen }}$ is computed (using Equation (5)) for 6C and 2C which is 0.2 nad 0.1 respectively. The FVM code was run for these two heat generation terms and the resulting temperature values in non-dimensional form was obtained. The temperature profiles from the experimental work was converted to non-dimensional form using Equation (5). The comparision between the present work and the experimental work for $Q_{g e n} 0.2$ and 0.1 is found to be having the same nature and the values are also very close.

Grid independence test is conducted to find out the most optimum number of grid points required in vertical and horizontal direction, both in solid and fluid domain. Three different grid size such as $82 \times 82,102$ $\times 102,122 \times 122$, and $142 \times 142$ for fluid domain and solid domain are selected for the grid independence test. The numerical results obtained for the non-dimensional temperature using above mentioned grid size for fluid and solid domain, the difference between the values of temperature for all the three grid sizes does not vary more than $5 \%$ which is clearly shown in Fig. 2 (c). In order to reduce the computational time and to catch the best possible steeper gradient of temperature without scarifying the accuracy of the results a grid size of $122 \times 122$ for solid domain and fluid domain is selected. 


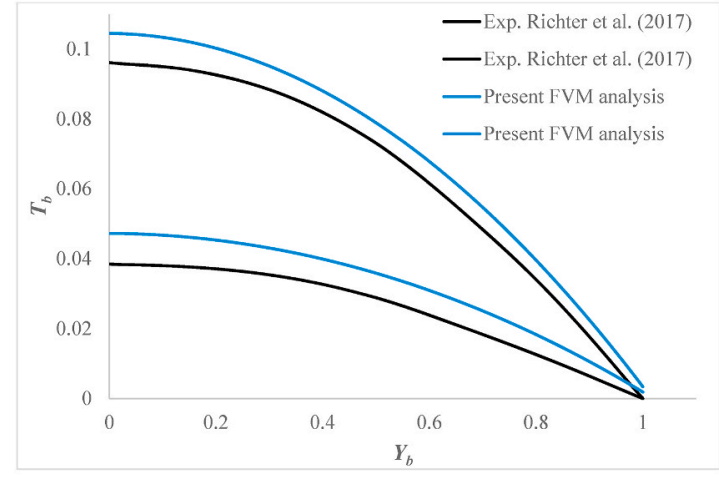

(a) Top two lines represent $Q_{g e n}=0.2$ and lower two lines represent $Q_{g e n}=0.1$

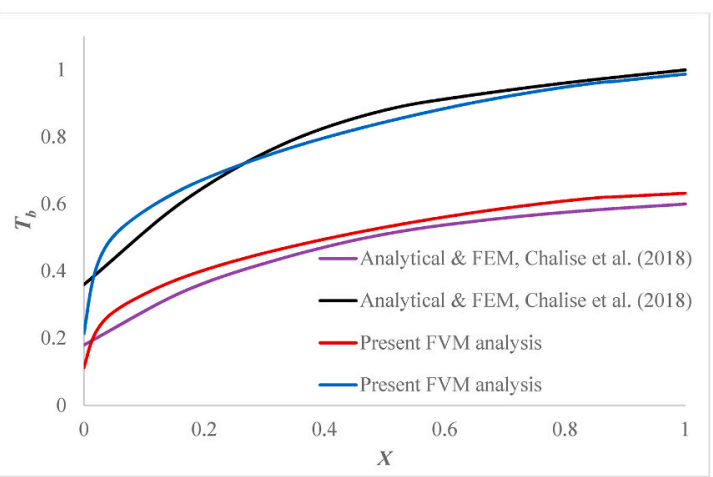

(b) Top two lines represent $Q_{g e n}=0.8$ and lower two lines represent $Q_{g e n}=0.4$

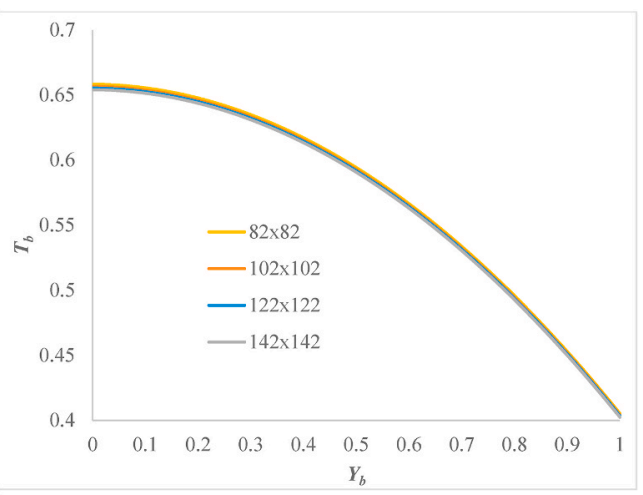

(c) Grid independence test for four grids

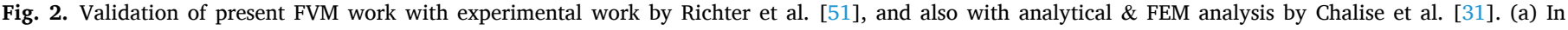
experimental work air is used as coolant fluid, $\mathrm{Pr}=0.7$ and (b) in FEM analysis, water is used as coolant (b) Pr $=6.9$. (c) grid independence test.

\section{Multiple back propagation (MBP) artificial neural network (ANN) modelling}

In this article, the back-propagation ANN model is modified [52], which is a new class of multi-layer FF network. The multi-layered FF network with back-propagation developed in this work is of three different types:

1. MBP 1: Feedforward (FF) having a multi-layered network with backpropagation

2. MBP 2: Integration of two FF network known as Multiple feedforward (MFF) having multi-layers with back-propagation

3. MBP 3: FF having multi-layers with back-propagation and connection between input and output layer

The working model of these above three MBPs are shown schematically in Fig. 3 (a) - (c). Also, the use of selective neurons for activation function in comparison with standard neuron is shown in Fig. 3 (d). The working of the above proposed MBP networks are explained as follows:

MBP 1: The FF having multiple hidden layers (2 in this case), and corresponding weight and bias functions are shown in Fig. 3 (a) are chosen initially arbitrarily. Upon experimentation, their values are finalized by back-propagation of the error. The normal multiplication of weights with input and addition of bias functions in each layer is followed with a suitable selection of activation function (sigmoidal in this case) mentioned in Equation (13). The error obtained after the guessed output and available real output is used for adjustments of weights. The MBP works on finding the minimum error function in weights, and back propagates it for learning purposes. Delta rule is used for the error function calculation [52,53].
$\Gamma_{x}=\frac{1}{1+e^{-N e t_{y}}}$

MBP 2: The integration of 2 FF networks, a central network, and a space network, provides a multiple feed-forward (MFF) network. The central network includes unique neurons with selective activation. These neurons are distinct from normal (standard neurons as shown in Fig. 3 d) neurons since they have an essential factor which is modified in conjunction with the training provided to the network so that they are able to identify patterns and respond to particular stimuli and ignoring the rest. To indicate whether and how much a neuron $z$ should contribute towards the network output, if a certain pattern $p$ is presented, a variable $\Theta_{z}^{a}$ in the neuron output equation may be incorporated.

$\eta_{z}^{a}=\Theta_{z}^{a} \Gamma_{z}\left(\psi_{z}^{a}\right)$

Neurons whose output is given by Equation (14) are selectively activated by neurons, as their contribution to the network output depends on the pattern of training data set. The problem is how the importance of each neuron should be assessed by means of selective activation or, in other words, how the values of several $\Theta_{z}^{a}$ should be determined. A feed-forward network named as space network may be used to solve, which has the same inputs as the network of selective activation neurons (main network) and the values of several $\Theta_{z}^{a}$ as outputs. The space network receives the input as the main network patterns and shows to the last neuron the importance of each neuron with the current pattern being selectively activated. With this, the space network divides the input space implicitly. Only after knowing the outputs from the space network can the main network calculate its output. Therefore, both networks are all working and need to be trained together, as shown 


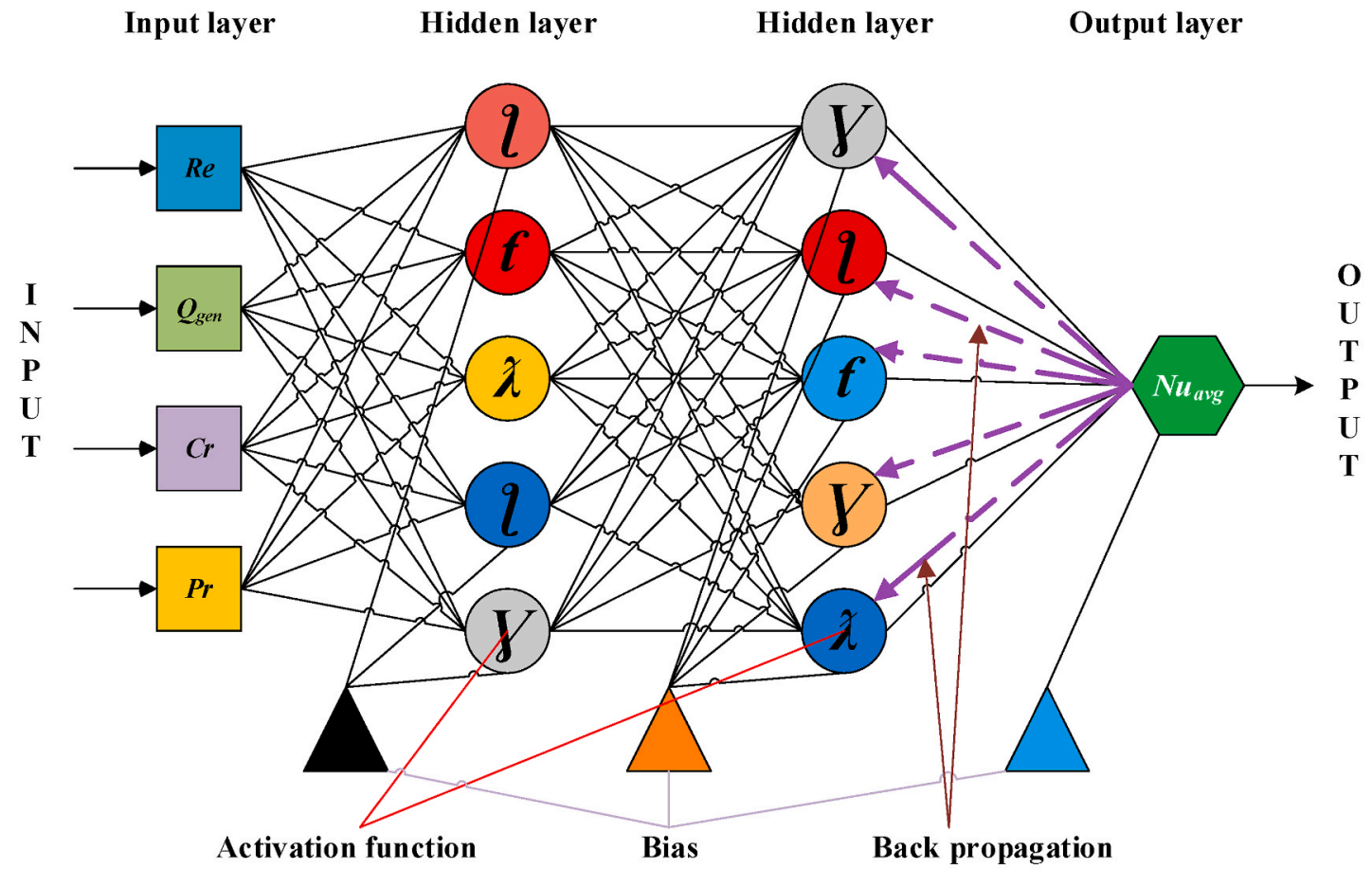

(a) feed-forward (FF) network having multi-layers with back-propagation: MBP 1

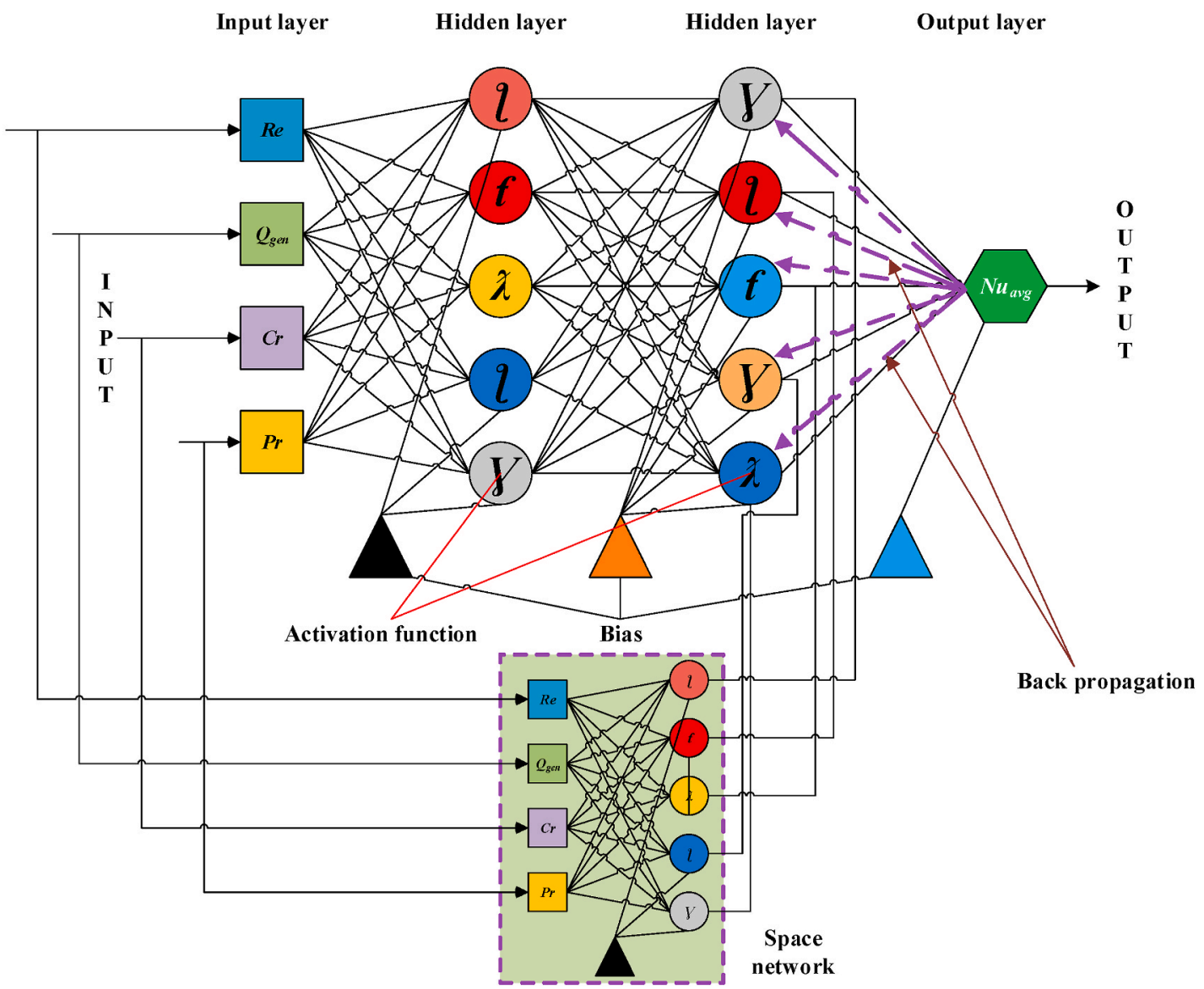

(b) integration of two FF network having multi-layers with back-propagation: MBP 2

Fig. 3. MBP networks used for training and testing of $N u_{a v g}$ from the obtained numerical values. 


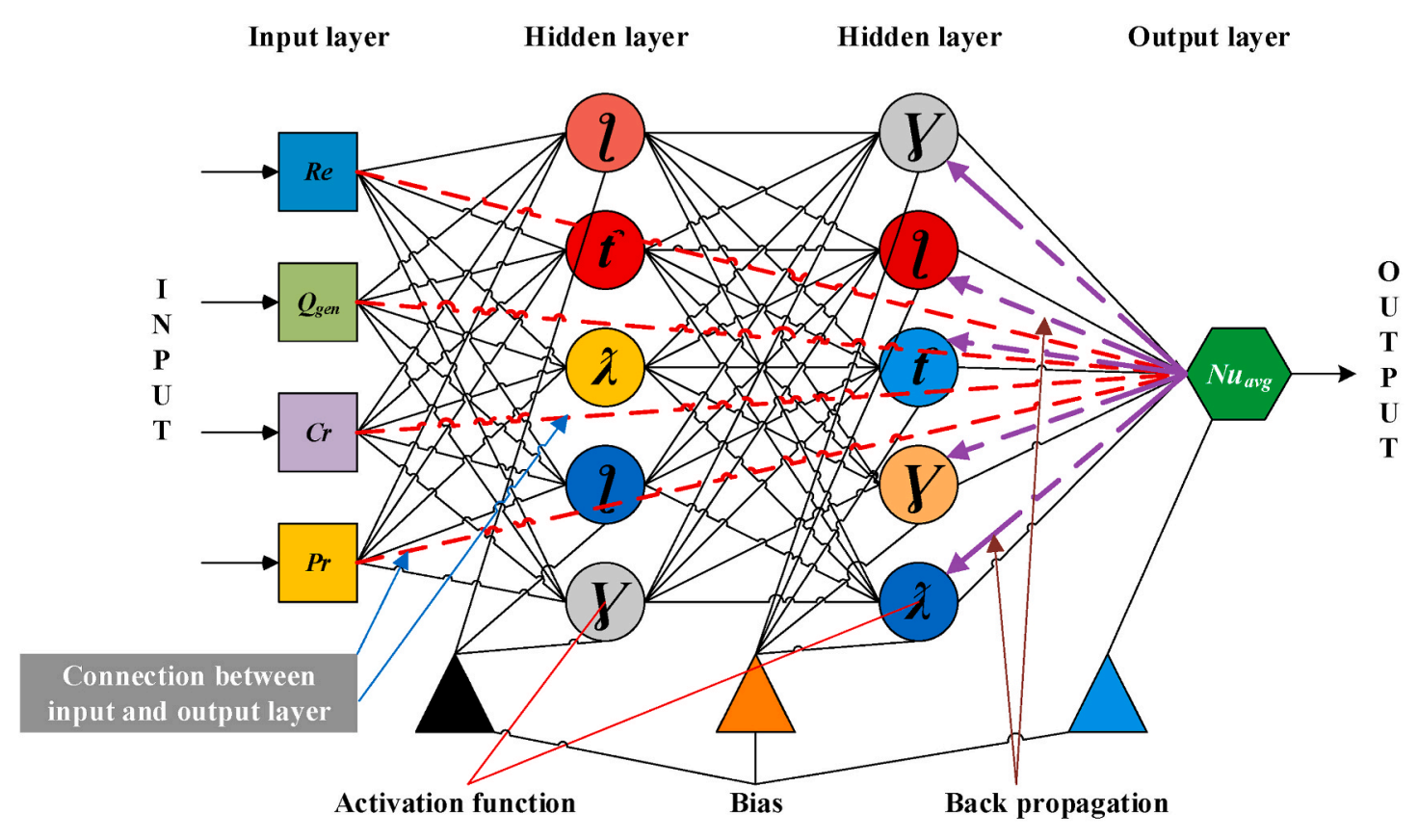

(c) FF network with multi-layers and back-propagation and connection between the input and output layer: MBP 3

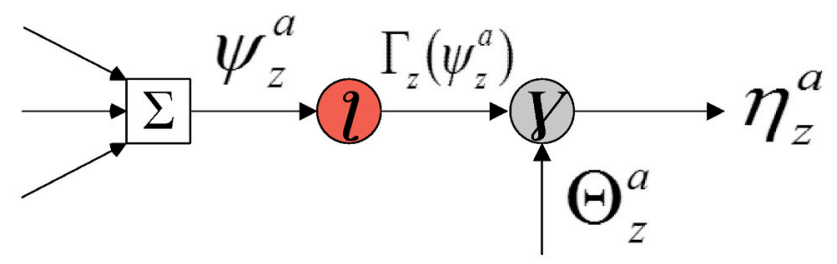

Neuron ' $z$ ' with selective activation

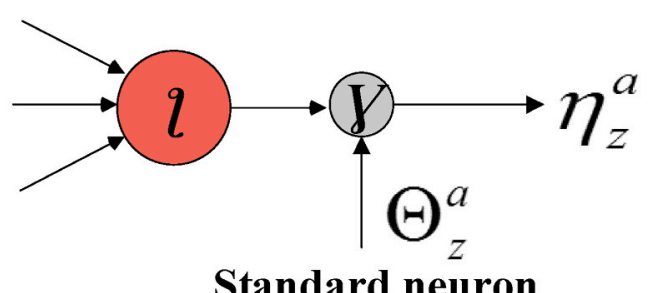

Standard neuron

(d) Use of selective activation neuron to adjust with pattern and a standard neuron

Fig. 3. (continued).

in Fig. 3 (b).

The output $\eta_{z}^{a}$ of such a network for a neuron $z$ with the pattern $a$ is given by:

$\eta_{z}^{a}=\Theta_{z}^{a} \Gamma_{z}\left(\psi_{z}^{a}\right)=\Theta_{z}^{a} \Gamma_{z}\left(\sum_{y=1}^{N} \omega_{y, z} \eta_{y}^{a}+\Phi_{z}\right)$

In Equation (15), the term $\Gamma_{z}^{a}$ is the activation function of neurons with $\psi_{z}^{a}$ as its activation. $\Theta_{z}^{a}$ is the essential factor, $\Phi_{z}$ is bias, and $\omega_{y, z}$ is the weight of connecting neuron $y$ and $z$. The essential factor is computed by the space network, receiving the same input as the main network.
In this method, back-propagation is employed for adjusting the weights employing the method of gradient descent given by Equation (16).

$\Delta_{a} \omega_{y, z}=\zeta \delta_{z}^{a} \eta_{y}^{a}+\chi \Delta_{b} \omega_{y, z}$

The learning rate is represented by $\zeta$ the local gradient is $\delta_{z}^{a}$ of neuron $z$, momentum term is $\chi$, and the last pattern fed to the network is $b$. For hidden neuron $n h$ and output neuron $n o$, the local gradients are given by Equation (17).

$\delta_{n o}^{a}=\left(d_{n o}^{a}-\eta_{n o}^{a}\right) \Theta_{n o}^{a} \Gamma_{n o}^{\prime \prime}\left(\psi_{n o}^{a}\right)$ 
$\delta_{n h}^{a}=\Theta_{n h}^{a} \Gamma_{n h}^{\prime \prime}\left(\psi_{n h}^{a}\right) \sum_{n o=1}^{N_{n o}} \delta_{n o}^{a} \omega_{n h, n o}$

Equation (16) and (17) allows the weights of the main network to adjust recursively. If one obtains $\Phi_{z}=1$, Equation (16) and (17) are the same as respective back-propagation equations. Hence this MBP is a type of generalized form of back-propagation network. The weights of the space network must also be regulated to minimize the errors. By doing so, we change the division of input space and look for a better and better division of space. The variation of essential factors can be calculated with the gradient descent method to adjust these weights.

$\Delta_{a} \psi_{z}^{a}=-\frac{\partial E^{a}}{\partial \psi_{z}^{a}}$

The above Equation (20) can be repeated for hidden and output neurons as:

$\Delta_{a} \psi_{n o}^{a}=\left(d_{n o}^{a}-\eta_{n o}^{a}\right) \Gamma_{n o}\left(\psi_{n o}^{a}\right)$

$\Delta_{a} \psi_{n h}^{a}=\sum_{n o=1}^{N_{n o}} \delta_{n o}^{a} \omega_{n h, n o} \Gamma_{n h}\left(\psi_{n h}^{a}\right)$

With this, the values for the space network $\left(\psi_{z}^{a}+\Delta_{a} \psi_{z}^{a}\right)$ are computed, and the back-propagation is applied to it. This composition of backpropagation and MFF can be preferred over a standard multi-layered FF network.

MBP 3: This model is similar to MBP 1, with a slight change of adding a connection between the input and output layer, as shown in Fig. 3 (c). This network demonstrates a direct involvement of input parameters to the guessed output. But the back-propagation is not direct but through the hidden layers, as explained previously. The generalized pseudo code of the MBP model is provided in algorithm 1.

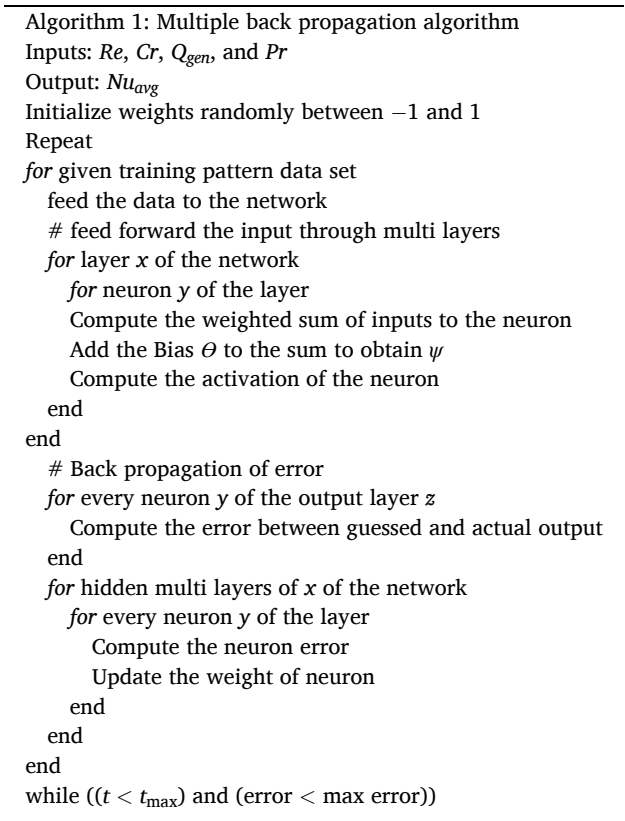

Based on the above proposed numerical methodology in section 2 and back propagation modelling, the present work is carried out in two phases. In the first phase the average $N u\left(N u_{a v g}\right)$ is obtained after solving the governing equations computationally. The FVM code developed is run for different input parametres sufficiently to get the $N u_{a v g}$. After collecting the entire data, MBP models are used for regression in the second phase. Using the proposed back propagation models (MBP 1, 2, and 3) the data obtained from the numerical analysis is feed to the network to carry out the regression analysis. The flow chart of the entire process followed for numerical computations and back propagation modelling is shown in Fig. 4.

\section{Results and discussions}

Average Nusselt number $\left(N u_{a v g}\right)$ indicating the ability of the system to remove heat from the pack and coolant interface is analyzed thoroughly for five categories of fluid coolants viz gases, common oils, thermal oils, nanofluids, and liquid metals at different Reynolds number and conductivity ratio. Initially, the temperature variation along the axial direction of the pack and along with coolant lateral direction, and maximum temperature variation is accessed for different conductivity ratio. In each category of coolant, five different fluids are employed for the analysis. The diverse range of conductivity ratio $(\mathrm{Cr})$ obtained based on the thermal conductivity of fluids in each category, i.e., $\mathrm{Cr}$ varies from 0.06 to 0.1 for gases, 0.06 to 0.9 for common oils, 0.1 to 1.2 for thermal oils, 0.1 to 2.0 for nanofluids, and 1 to 5 for liquid metals is decided. The Prandtl number of coolants in category belongs to a particular fluid. In Table 1, the Pr of each coolant belonging to different categories is mentioned.

MWCNT (multi-walled carbon nanotubes), $\mathrm{TiO}_{2}$ (titanium dioxide), $\mathrm{Al}_{2} \mathrm{O}_{3}$ (aluminum dioxide), and $\mathrm{CuO}$ (copper oxide) are the nanofluids prepared in water as base fluid with $0.1 \%$ volume concentration (\%vol.), and their Pr is obtained based on data from different sources [54-57].

\subsection{Temperature distribution and maximum temperature}

Fig. 5 illustrates the effect of conductivity ratio on the temperature profiles of battery pack at its center along the transverse direction while the parameters like Reynolds number, total heat generation, and Prandtl number within the battery pack remains constant. It is observed from Fig. 5 that with an increase in the conductivity ratio, the temperature within the battery pack decreases. Such behavior in the temperature of the battery pack may be attributed to the fact that an increase in the conductivity ratio increases the rate of heat flow through the fluid medium, thus allowing the temperature of the battery pack to drop. One more observation made from above Fig. 5 that there is an upper limit of conductivity ratio beyond which the temperature of the battery pack marginally decreases. The temperature within the battery pack increases along the height of the battery pack and reaches its maximum value near the battery top portion i.e. near $X_{b}=1.0$, irrespective of the conductivity ratio. At exactly $X_{b}=1.0$ there is sudden drop in temperature as the heat is transferred from the top of battery by convection. When the coolant flows past the battery pack it enters with its base temperature and as the coolant travels through the battery pack its temperature increases due to transfer of heat from the battery to the coolant. This further tends to affect the temperature difference between the battery and coolant. The heat transfer between the coolant and battery pack is thus reduced due to the reduction of the temperature difference as the coolant reaches the trailing edge. Hence this reduces the rate of heat flow through it, which finally appears in the form of increase in the temperature at the trailing edge of the battery.

Fig. 6 depicts the influence of conductivity ratio on coolant (water) temperature away from the battery pack in the lateral direction, and the parameters like Reynolds number, total heat generation are kept at their base value. It is clear from Fig. 6 that with an increase in the conductivity ratio, the temperature within the coolant laterally away from the battery pack decreases. The decrease in the temperature of the coolant is observed strongly up to a lateral distance of $Y_{f}=1.075$, and above this value, the drop in temperature of the coolant is negligible. Such behavior of coolant temperature implies that as the lateral distance from the battery pack increases, the thickness of the fluid domain also increases, which may tend to dominate the coolant ability to carry the heat irrespective of the conductivity ratio.

From Fig. 6 it is also pretty clear that the temperature of the coolant is brought down by an increase in Cr. This is owing to the fact that an 


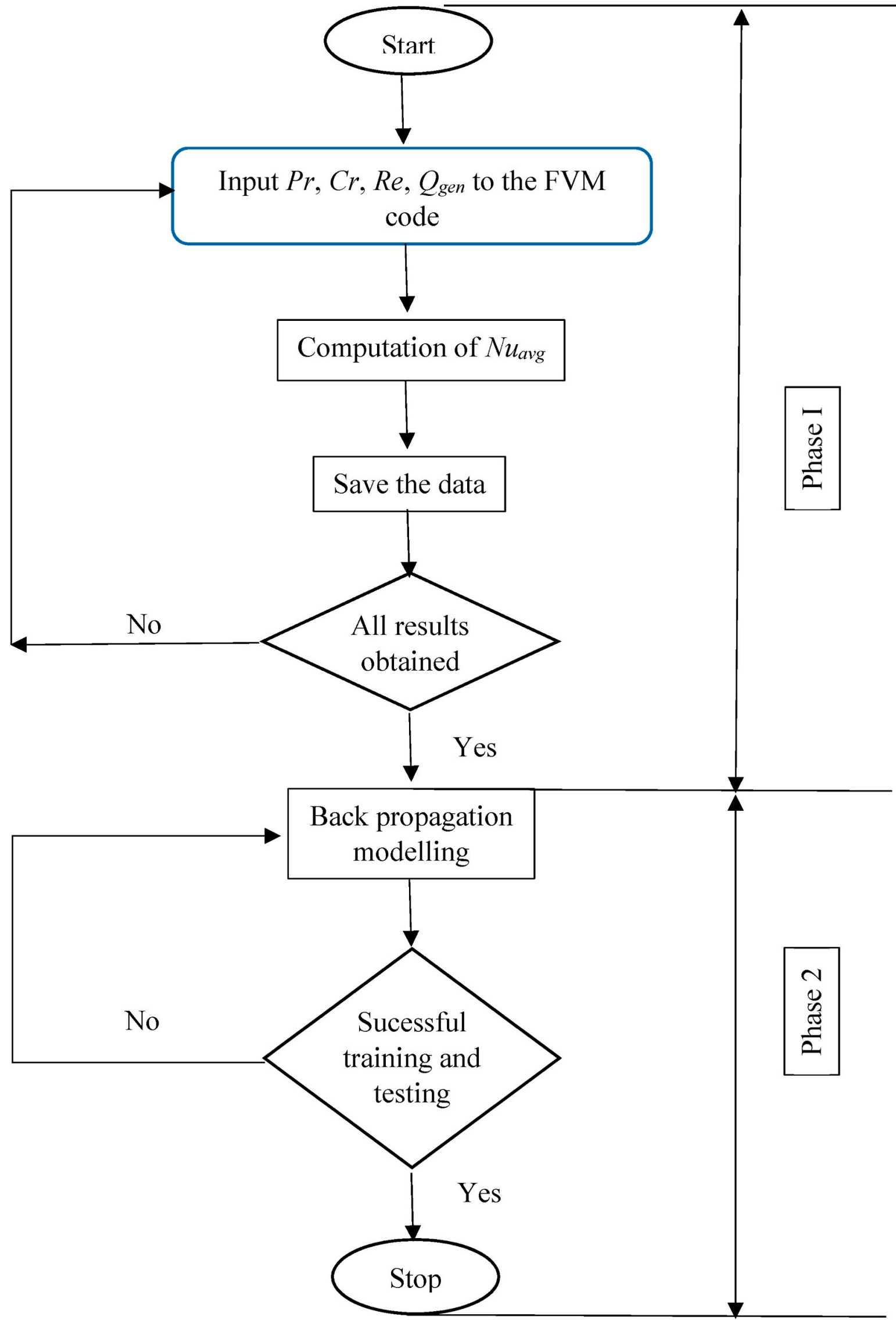

Fig. 4. Flowchart of the present work involving CFD analysis and back propagation modelling. 
Table 1

Pr number of five fluids belonging to each category of coolant.

\begin{tabular}{|c|c|c|c|c|c|c|}
\hline \multicolumn{2}{|l|}{ Gases } & & \multicolumn{2}{|l|}{ Common oils } & \multicolumn{2}{|l|}{ Thermal oils } \\
\hline Coolant name & $\operatorname{Pr}$ & & Coolant name & $\operatorname{Pr}$ & $\begin{array}{l}\text { Coolant } \\
\text { name }\end{array}$ & $\operatorname{Pr}$ \\
\hline Air & 0.7 & & $\begin{array}{l}\text { EG (ethylene } \\
\text { glycol) }\end{array}$ & 40.36 & $\begin{array}{l}\text { Therminol } \\
55\end{array}$ & 38.4 \\
\hline Argon & 0.68 & & $\begin{array}{l}\text { Mineral oil (10- } \\
\text { NF) }\end{array}$ & 511.5 & Dowtherm & 37.25 \\
\hline Helium & 0.666 & & $\begin{array}{l}\text { Dielectric oil (FC- } \\
\text { 77) }\end{array}$ & 21.7 & $\begin{array}{l}\text { Syltherm } \\
800\end{array}$ & 101.5 \\
\hline hydrogen & 0.6577 & & Silicon oil $(\mathrm{M}-3)$ & 25.2 & Dowcal 100 & 200.86 \\
\hline $\begin{array}{l}\text { Carbon } \\
\text { dioxide }\end{array}$ & 0.941 & & Novec 7000 & 7.76 & Dowfrost & 13.67 \\
\hline \multicolumn{3}{|l|}{ Nanofluids } & \multicolumn{4}{|l|}{ Liquid metals } \\
\hline Coolant name & & $\operatorname{Pr}$ & Coolant nam & & & $\operatorname{Pr}$ \\
\hline \multicolumn{2}{|l|}{ MWCNT $0.1 \%$ vol. } & 3.24 & \multirow{2}{*}{\multicolumn{3}{|c|}{$\begin{array}{l}\mathrm{Ga}^{68} \mathrm{In}^{20} \mathrm{Sn}^{12} \text { (Gallium, indium, tin) } \\
\mathrm{Na}^{27} \mathrm{~K}^{78} \text { (sodium-potassium) }\end{array}$}} & 0.0208 \\
\hline \multicolumn{2}{|l|}{$\mathrm{TiO}_{2}$ 0.1\%vol. } & 4.33 & & & & 0.0411 \\
\hline $\mathrm{Al}_{2} \mathrm{O}_{3} \quad 0.1 \%$ vol. & & 4.17 & \multicolumn{3}{|c|}{ Ga (Gallium) } & 0.0264 \\
\hline \multicolumn{2}{|l|}{$\mathrm{CuO} 0.1 \%$ vol. } & 5.24 & \multicolumn{3}{|c|}{ Galinstan (eutectic alloys) } & 0.0436 \\
\hline \multicolumn{2}{|l|}{ Water } & 6.9 & \multicolumn{3}{|c|}{ GaIn $^{20}$} & 0.0303 \\
\hline
\end{tabular}

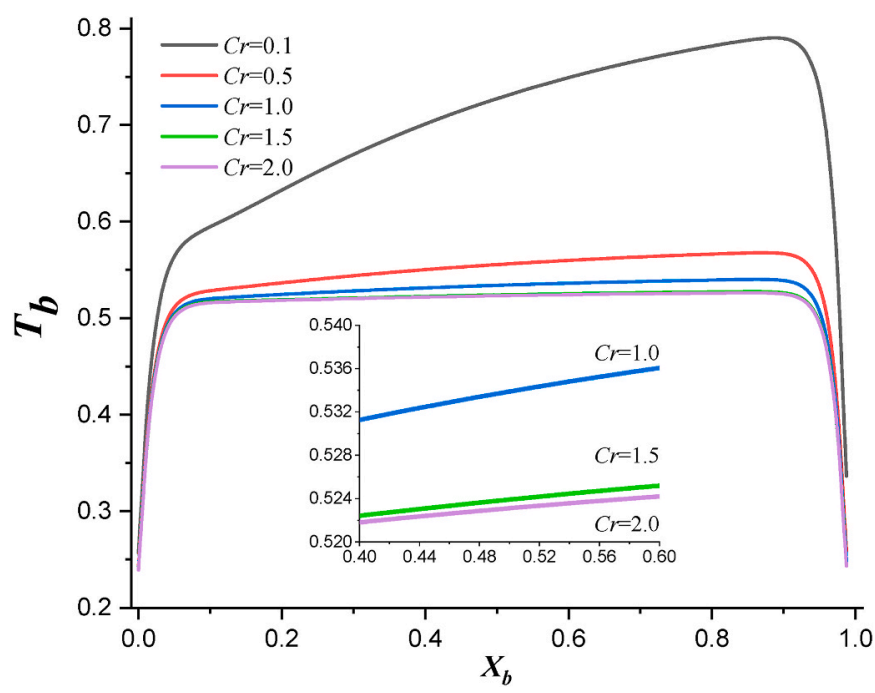

Fig. 5. The temperature in battery pack at the center of the battery pack from bottom to top at different conductivity ratios.

increase in $\mathrm{Cr}$ is related to an increase in the coolant's thermal conductivity, which in turn results in a comparatively higher heat dissipation rate from the battery to the coolant. However, as the heat produced inside the battery is fixed, the temperature of the battery will decrease, followed by a decrease in the coolant temperature. The foregoing statement is clearly evident in this figure, in accordance with the specific nature of the transverse temperature profiles. It can be easily established from the figure that the fluid temperature gradient on the battery surface decreases with an increase in $\mathrm{Cr}$, which is in turn is correlated with a drop in the surface heat dissipation rate induced by a drop in the temperature of the battery due to higher $\mathrm{Cr}$ as described above. Furthermore, it is obvious from this figure that as $\mathrm{Cr}$ increases, the rate of reduction in coolant temperature also tends to decrease, and from this figure it can comfortably be deduced that there is an upper limit value of $\mathrm{Cr}$ after which further reduction in coolant temperature becomes relatively small. Perhaps, if the thermal conductivity of battery is not changed then a situation arises in which just mere increase in $\mathrm{Cr}$ will not further increase the heat dissipation rate from the battery. Hence in such situation Reynolds number of the coolant can be increased to achieve better rate of heat transfer from the battery pack but at the cost of high pumping work.

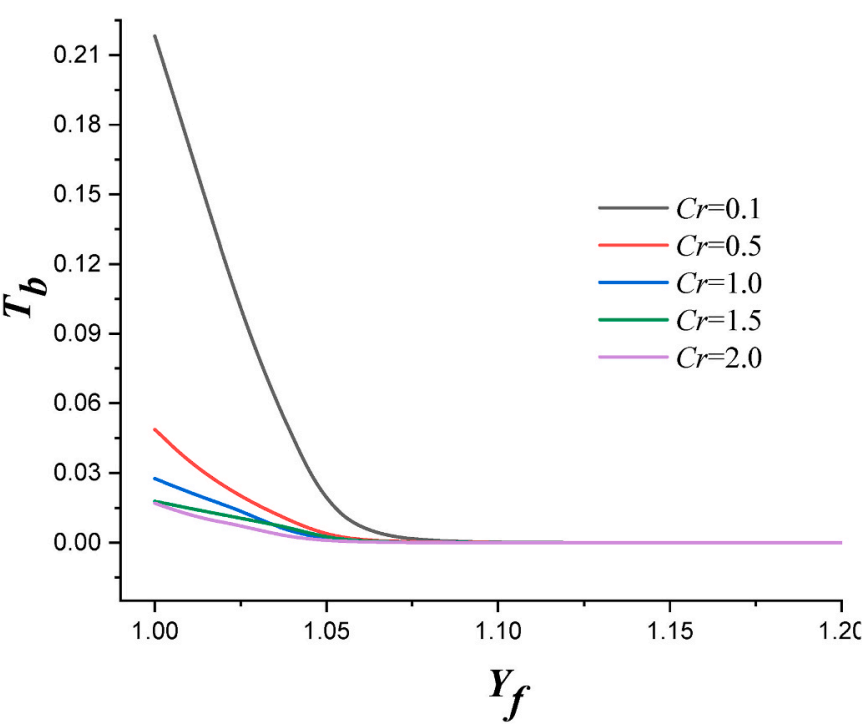

Fig. 6. Temperature in coolant water channel away from the battery laterally at the mid-height at different conductivity ratios.

The transverse and longitudinal velocity distribution profiles over the battery cell in the boundary layer at different locations when $\mathrm{Re}=$ 750 is shown in Fig. 7 (a) and 7 (b) respectively. It can be seen in Fig. 7 (a) that the transverse velocity, first rises near the leading edge and then reduces as the fluid travels away from the bottom. We know that fluid particles are entrained near the leading edge as the fluid enters over the surface, and then decrease as it travels away from the leading edge. At low Re the retardation of the fluid motion is less in the transverse direction near the leading edge and then this raises proportionally with rise in $R e$. The $U$ velocity profiles along the axial direction at different longitudinal locations on a battery cell shown in Fig. 7 (b) depicts the growth of velocity boundary layer. Similar to those near the trailing edge, the $U$ velocity gradients are higher on the leading edge. A further interesting aspect is that among downstream sites, the $U$ velocities at $\mathrm{X}$ $=0.5$ and $\mathrm{X}=0.75$ are nearly identical and coincide. This affirms that the flow is fully developed in hydrodynamic form.

Fig. 8 illustrates the variation in maximum temperature of the battery pack with the Reynolds number and conductivity ratio, and the parameters like total heat generation in the battery pack is kept constant. Increase in the Reynolds number of the flowing fluid as well as conductivity ratio of fluid to solid domain the maximum temperature in a battery pack decreases. An increase in the Reynolds number increases the flow velocity of the fluid, which further increases the convective heat transfer coefficient hence leading to reduce the maximum temperature in the battery pack. As water is used as a coolant, therefore the viscous force within the fluid is easily dominated by the inertia force, and this dominancy of inertia force is visualized at Reynolds number 500. From Fig. 8 it is seen that $\mathrm{t} e>1000$, the drop in maximum temperature of the battery pack is very small. This indicates that there exists a higher limiting value of Reynolds number irrespective of conductivity ratio above which the drop in maximum temperature is negligible. Because the heat that can removed by the coolant cannot be more than the heat generated inside the battery. Hence, a best suitable range of the Reynolds number is of prime importance keeping pump capacity at prime importance. As seen from Fig. 8, at low Reynolds number $(<500)$ and conductivity ratio $(=0.1)$, the maximum temperature within the battery pack cross its safer limit $(=1)$ as the coolant cannot carry sufficiently the heat generated. This will result in deterioration in the performance of the batteries. Hence a lower limiting value of Reynolds number and conductivity ratio exists. If they are reduced below this lower limiting value, the temperature rises above the safe limit resulting in thermal runaway. 


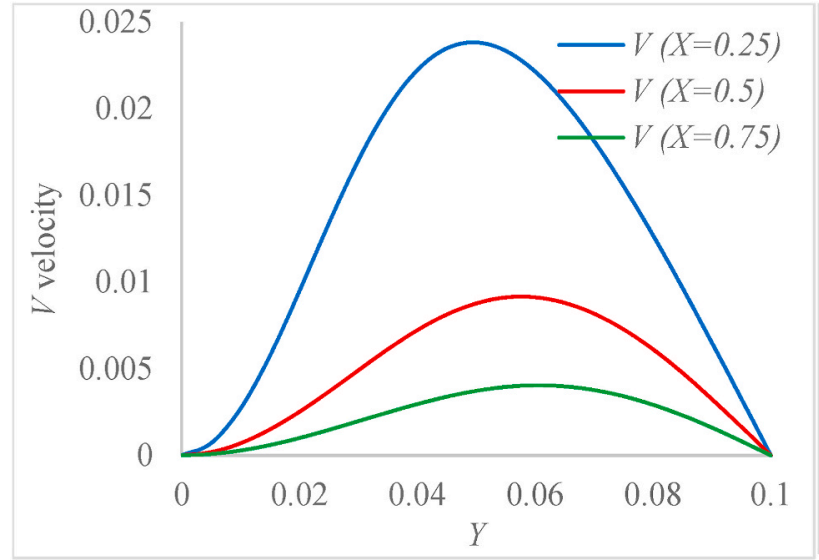

(a) Transverse velocity profiles on a battery cell

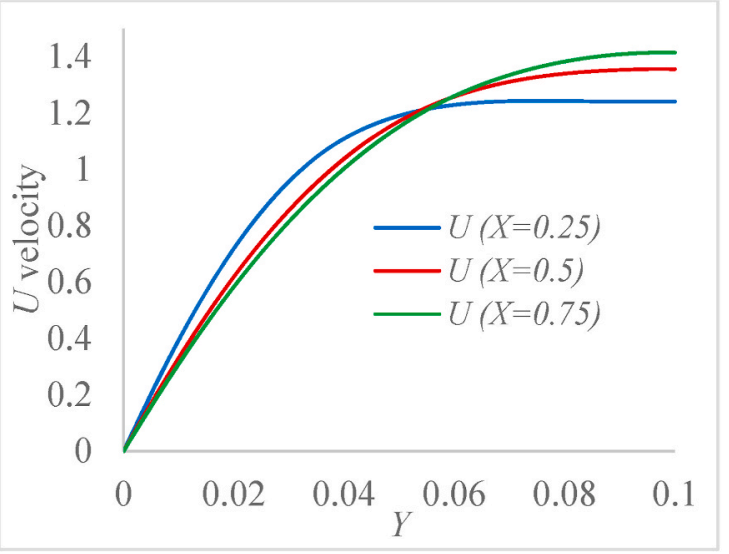

(b) Longitudinal velocity profiles on a battery cell

Fig. 7. $U$ and $V$ velocity at different locations along the channel.

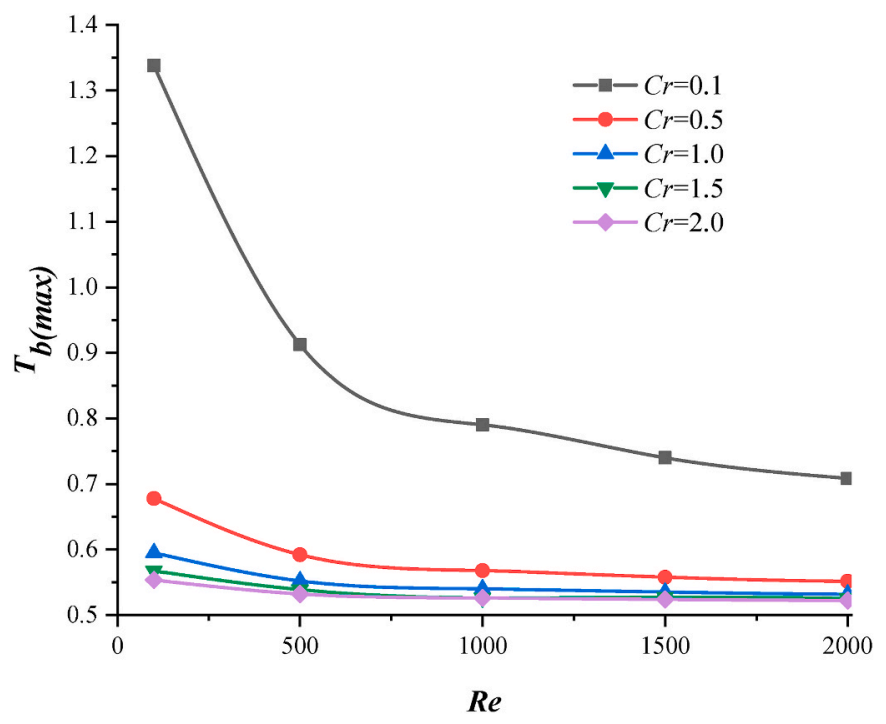

Fig. 8. Maximum temperature in battery pack varying with $\mathrm{Re}$ and $\mathrm{Cr}$ with water as coolant and at different conductivity ratios.

\subsection{Average Nusselt number analysis}

In Fig. 9, the effect of Reynolds number on average Nusselt number for two different coolant (water and air) for various heat generation rates is depicted. As expected with an increase in the Reynolds number, the average Nusselt number for water and air also increases. The heat dissipation is significantly improved with the Reynolds number which indicate this rise in Nusselt number. For water after Reynolds number 1000 , Nusselt number remained same as the heat removal from battery cannot be increased way beyond the heat generated inside it. But one more observation to be made is that increase in the heat generation rate within the battery pack does not make any difference in Nusselt number. This nature of negligible effect of heat generation rate on Nusselt number is quite interesting to know. It is well known fact that with the increase of heat generation rate the temperature of battery increases. The temperature at the interface also tends to increase with increasing heat generation. Surprisingly enough, irrespective of location along stream-wise the interface of battery-coolant temperature $\left(T_{Y b=W b}\right)$ and its normal derivative (both in Equation (12)) reduce in such a way that,

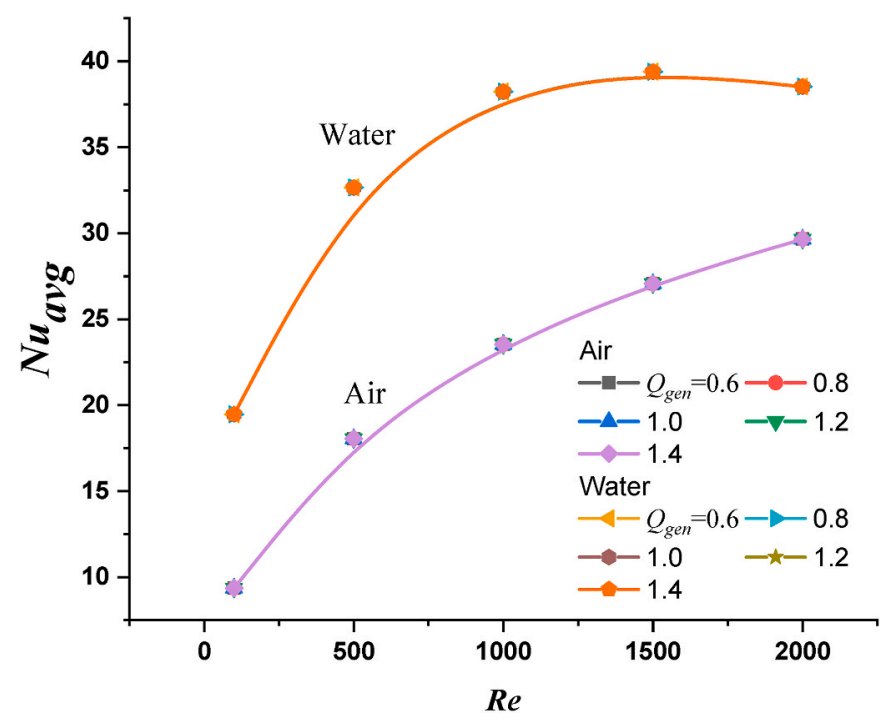

Fig. 9. $N u_{\text {avg }}$ for different Reynolds number with water and air as a coolant at different heat generation. For water and air the $N u_{a v g}$ is the same for different heat generation.

they remain almost constant which are related to Nusselt number. With the increase of heat generation rate, the rise in interface temperature $\left(T_{Y b=W b}\right)$ at every stream-wise location and the normal derivative, maintain their ratio exactly same. Hence it can be said that the Nusselt number is independent of the heat generation rate within the battery pack. As expected, water proves to be a good coolant as it results in a high average Nusselt number compare to air for the same rate of increase in the Reynolds number. But an increase in the amount of heat transfer rate from the battery pack for water as a coolant compares to air will be at the cost of high pumping power.

Fig. 10 (a) and (b) depicts the effect of Reynolds number on average Nusselt number for fluids such as gases, oils, and for thermal oils, nanofluids, and liquid metals, respectively. From Fig. 10 (a), it is clear that when gases are used as a cooling fluid, the nature of the behavior of gases irrespective of their Prandtl number remains the same. The highest value of the average Nusselt number is observed for the corresponding highest value of Reynolds number and Prandtl number, which implies the dependency of the Nusselt number. Hence it can be suggested to use 


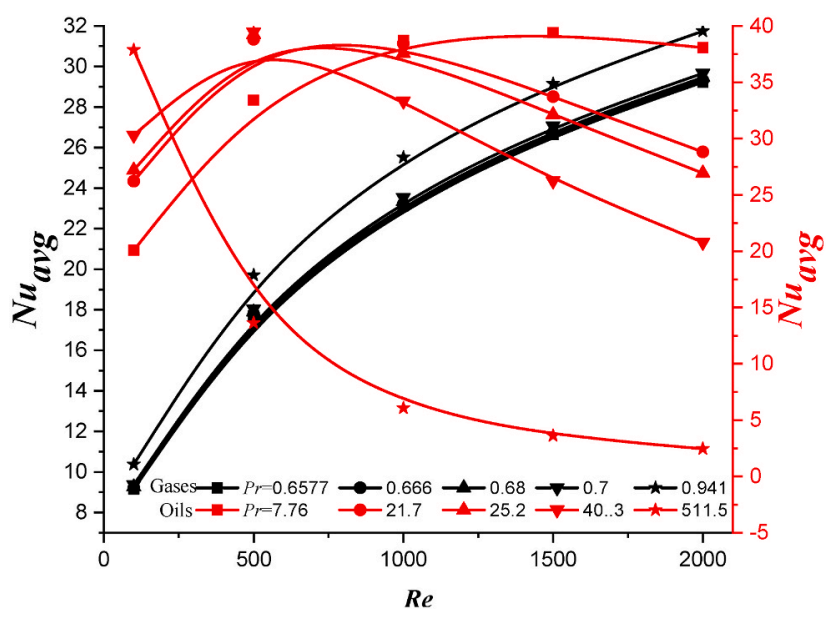

(a) Nuavg for different $R e$ with gases and oils as coolants

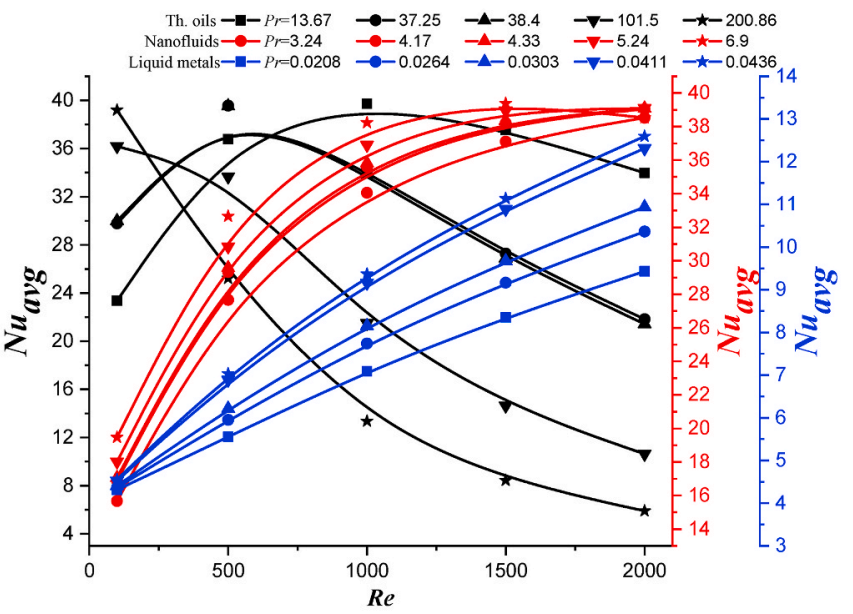

(b) Nuavg for different Re with thermal oils, nanofluids, and liquid metals as coolant

Fig. 10. Variation in $N u_{a v g}$ with a change in Pr and Re.

gases as a coolant in a battery thermal management system with an appropriate range of Reynolds and Prandtl number. But the behavior of oils is completely different as compare to gases except for the oil with low Prandtl number. For oils with low Prandtl number an increase in the Nusselt number for the corresponding increase in Reynolds number is observed. Oils with higher Prandtl value (21-512) initially show an increase in Nusselt number, but as the Reynolds number reaches a value greater than 500, the drop in Nusselt number is observed such behavior shows the influence of Prandtl number on the heat transfer rate of the battery system. Therefore it is better to use oils as a coolant with low Reynolds and Prandtl number in order to achieve better cooling effects.

Again looking at Fig. 10 (b), it is clear that for coolants such as nanofluids and liquid metals, the average Nusselt number is increasing with the increase in Reynolds and Prandtl Numbers, but a contrary effect is observed in case of thermal oils. From Fig. 10 (b) it is seen that for very high Prandtl number i.e. $>100$ with increase in Reynolds number, the Nusselt number decreases. This is because the coolants are more viscous and have high specific heat capacity causing inefficient heat transfer from the battery surface which becomes more prominent with increasing Reynolds number. Therefore the corresponding Nusselt number also reduces. However interesting pattern is observed for coolants with Prandtl number $<50$. A rising trend and then decreasing with increasing Reynolds number is seen. If the coolant flows faster, due to the oil thickness the heat transfer becomes deteriorated. As the Prandtl number is kept on reducing the oil becomes less viscous and at low flow Reynolds number the heat transfer becomes efficient. Hence the Nusselt number rises initially and then decreases with flow velocity. From both
Fig. 10 (a) and (b) collectively, it can be said that to maintain an efficient and better cooling of the battery pack, it is necessary to choose a desirable range of Re and Pr for corresponding coolants.

In Fig. 11, the average Nusselt number with Reynolds number and different categories of coolants are shown. The conductivity ratio of gases, oils, thermal oils, nanofluids, and metal coolants are also varied in a specified range. The effect of conductivity ratio is negligible as the velocity profiles remain unchanged with an increased in it. The main reason behind this is the ratio of interface temperature and its normal derivative being remain same as explained previously with respect to Fig. 8. For an increase in Reynolds number, the Nusselt number obviously increases due to enhancement in heat transfer with the velocity enhancement of coolant flowing over the battery pack. But when highly viscous oils (common oils and thermal oils) are passed over the pack, the behavior is very contrary. The increased Prandtl number of coolant show reduction in average Nusselt number with an increase in Reynolds number. The momentum diffusivity being dominant in oils causes a reduction in thermal diffusivity, which produces reduced average Nusselt number. However, for higher Prandtl number and lower Reynolds number, the average Nusselt number is quite higher as the fluid has more specific heat capacity needing more time to diffuse the heat into the oil. If Reynolds number increases, the heat does not diffuse efficiently and hence causes faster flowing fluids to not absorb more heat. Therefore, for higher Prandtl number lower Reynolds number is suitable while for lower Prandtl number fluids, higher Reynolds number is required.

Fig. 12 illustrates the effect of the Heat generation parameter on average Nusselt number for various conductivity ratios of different coolants while the Reynolds and Prandtl numbers are kept constant. It is clearly observed from the above Fig. 12 that with an increase in heat generation rate within the battery pack as well as with an increase in conductivity ratio, no change in Nusselt number is seen irrespective of all the coolants considered in this study. Conductivity ratio does not affect the flow distribution due to which the ratio of temperature change and temperature gradient at the interface remains constant. Though the heat removal is significantly improved with the increase of conductivity ratio, but the proportionate increase in normal derivative of temperature gives a constant local Nusselt number which is in line with the preceeding results explained for Fig. 9. Therefore the average Nusselt number with change in conductivity ratio is unaffected. However, it is observed that Nusselt number for coolants such as oils and nanofluids it

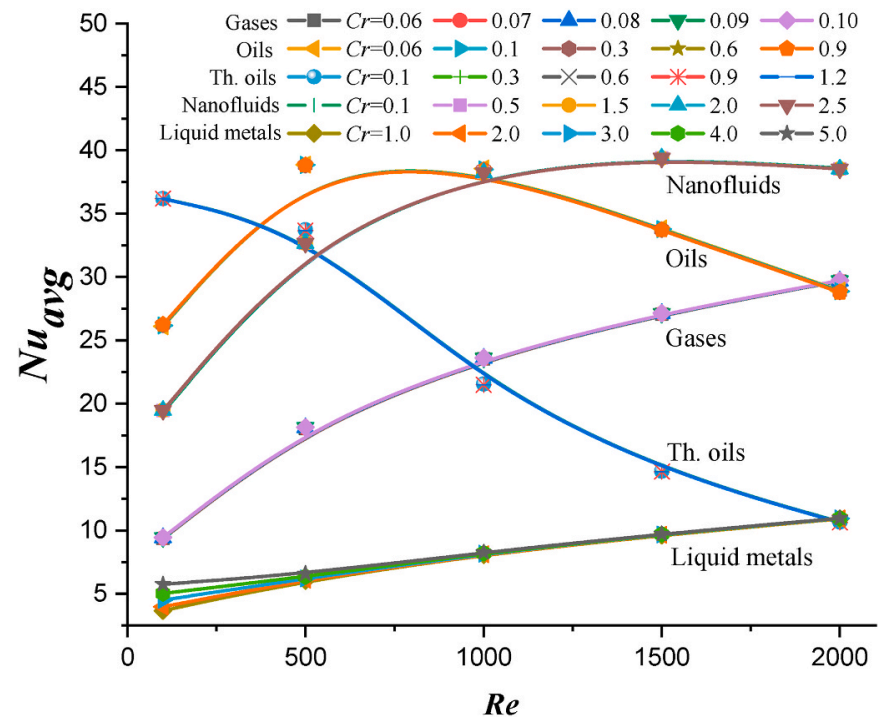

Fig. 11. $N u_{a v g}$ for different Re and $\mathrm{Cr}$ belonging to five classes of coolants. $\mathrm{Cr}$ does not impact $\mathrm{Nu}_{\text {avg, }}$, but Re either increases or decreases depending upon coolant category $(\mathrm{Pr})$. 


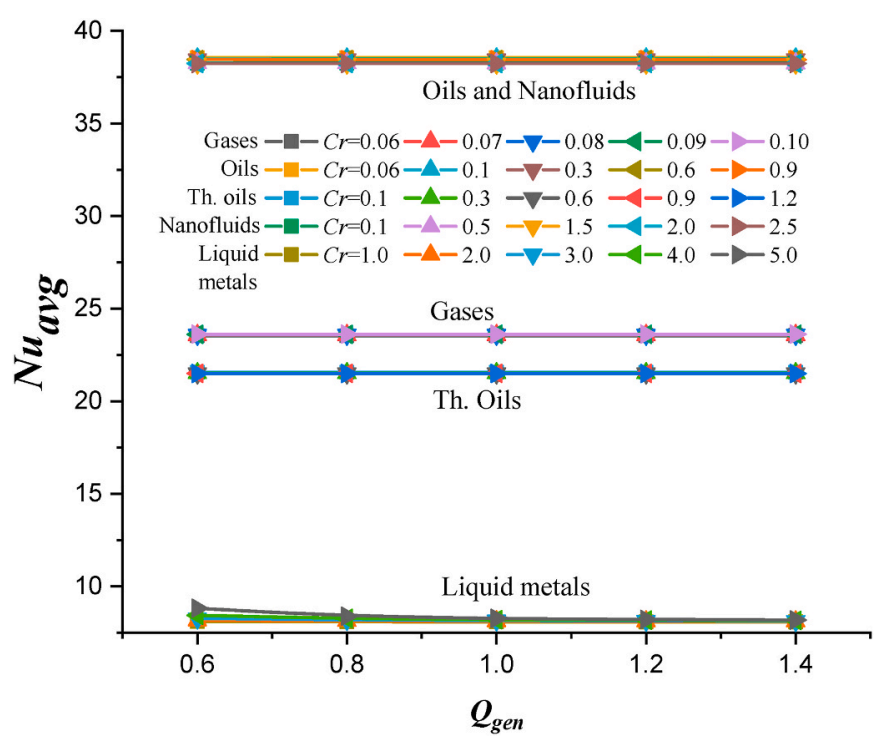

Fig. 12. No effect of different heat generation term on $N u_{\text {avg }}$ whereas oils and nanofluids have shown maximum $N u_{a v g}$.

is found to be maximum, for coolants like gases and thermal oil a moderate level of Nusselt number is seen and finally for liquid metal coolants the minimum Nusselt number is approached. Such behavior in Nusselt number is due to a change in conductivity ratio as well as the Prandtl number of each coolant, which may tend to influence the heat transfer characteristics of a coolant.

Fig. 13 (a) - (e) elucidate the effect of total heat generation parameter on average Nusselt number for various coolants having a wide range of Prandtl numbers with constant flow Reynolds number and Conductivity ratio. It is observed from Fig. 13 (a) that the total heat generation within the battery pack does not make any change in average Nusselt number irrespective of all the coolants. It is observed that for gases having $\operatorname{Pr}<$ 1 , the average Nusselt number increases with an increase in Prandtl number, and it reaches a maximum value for $\operatorname{Pr}=0.941$. In contrast to gases, for oils, the average Nusselt number decreases with an increase in the Prandtl number and reaches a minimum value at $\operatorname{Pr}=511.5$ as shown in Fig. 13 (b). The contrasting behavior of the oils is mainly due to the dominating nature of momentum diffusivity over thermal diffusivity. Hence oils will act as poor heat transferring medium.

From Fig. 13 (c)-(e), it is observed that for thermal oils with an increase in the Prandtl number, the average Nusselt number decreases while for nanofluids and liquid-metals, the average Nusselt number increases with increase in the Prandtl number. It is also observed that the maximum value of the average Nusselt number is observed for thermal oils with $\operatorname{Pr}=13.67$. From Fig. 13 (d) it is seen that the average Nusselt number for nanofluids is batter than the oils and gases. Nanofluids are thinner and less viscous than oils. Heat can easily diffuse at faster rate hence the average Nusselt number is increasing with nanofluid Prandtl number. Nanofluids will also need less pumping power then oils. From Fig. 13 (e) the average Nusselt number for different liquid metal coolants is see to be reducing. The overlapping thermal boundary in liquid metal coolant flow reduce the heat transfer. Hence a further investigation to know the effect of channel width is important. If we carefully observed the behavior of each coolant, the nanofluids will be a good choice for the thermal management of a battery pack compared to other coolants.

The effect of conductivity ratio on average Nusselt number of various coolants such as gases, oils, thermal oils, nanofluids, and liquid-metals is as shown in Fig. 14 (a), (b), (c), (d) and (e) respectively, while the total heat generation rate within the battery pack and flow Reynolds number are being kept at their base value. It is observed from the above figures that with an increase in the conductivity ratio, the average Nusselt number increases very marginally with the exception for liquid-metal coolants where for the lower value of Prandtl number a notable increase in the average Nusselt number is seen. The coolants like oils, thermal oils, and nanofluids having a Prandtl number in the range of 6-14 show a maximum drift in the average Nusselt number compare to coolants like gases and liquid metals having a very low range of Prandtl number. It is also observed from the above figures that when gases are used as a coolant, the gas with a high range of Prandtl numbers will suffice while if we look at the oils, thermal oils the low range of Prandtl number is good for better thermal management of battery system. Lastly, if we look at the liquid metal coolants due to their high density, they may not be considered as a good choice for cooling. If we talk in terms of heat transfer characteristics as well as the efficient performance of battery system it is advisable to use nanofluids as a coolant while all other coolants may enhance the heat transfer rate but at the cost of pumping power and poor performance, which will be not a good choice.

\subsection{Regression using the proposed MBP networks}

The MBP models used for the prediction of $N u_{a v g}$ is carried out in two phases. The numerical values of $N u_{\text {avg }}$ obtained are 650 in number. Out of this, 625 values of each variable are used for training and learning the models, and 25 values are used for testing the trained MBP models. The momentum and learning rate for all the models, as well as the space network, is initialized to 0.7 . The root means square (RMS) error must be as low as possible for a more accurate prediction of the output. The RMS with respect to iterations is shown in Fig. 15 (a) for all the models. The RMS values for the space network are all depicted. The RMS error for all models is less than 0.1, while only for space network is higher, indicating that even after 10,000 iterations, the weights were unable to adjust for proper training of the network. However, the predicted values from the network in comparison with the actual values shown in Fig. 15 (b)-(d) indicate a higher level of fit. The outliers are a few to note that can be exempted. Much of the data is found to be trained well for the given input values, and hence the training is found to be successful.

In the second phase, the trained network is tested with known output values of $N u_{\text {avg. }}$. The output from the trained network was obtained by feeding only the inputs to the network. These outputs were compared with the known 25 output values, as shown in Fig. 15 (e)-(g). The tested values and desired output values for the three networks show that MBP 1 has a closer prediction of $N u_{\text {avg }}$ than the other two. A look at Fig. 15 (e)(g) reveals that at pattern between 1 and 10 the MBP 1 has very close output to the desired output. And at pattern 17 to 25 the MBP 1 gives closer values to desired output. The network MBP 2 and MBP 3 have predicted nearly the same. However, MBP 2 and MBP 3 at these patterns do not provide a close match with the desired output as provided by MBP 1 . Hence MBP 1 at all patterns predicts more closely than the other networks. The RMS error of MBP 1 is very minimal compared to the other two. The output by MBP 2 and MBP 3 are also inline with the trend of the desired output but with a slight mismatch. This has clearly indicated that a multi-layered feed-forward network predicts the $\mathrm{Nu}_{\text {avg }}$ of the battery pack and coolant comfortably irrespective of any kind of network design. The weights and bias functions obtained for the network MBP 2 are provided in Table 2. These values of weights and bias can be used for prediction $\mathrm{Nu}_{\text {avg }}$ for a given change in input $\mathrm{Re}, \mathrm{Cr}, \mathrm{Q}_{\mathrm{gen}}$, and $\mathrm{Pr}$.

\section{Conclusions}

In this article, the heat removal from the battery pack in the form of an average Nusselt number is analyzed in detail, considering coupled heat transfer conditions at the pack and coolant interface. Five categories of coolant, i.e., gases, oils, thermal oils, nanofluids, and metal coolants, are used for analysis. For variation in conductivity ratio and Reynolds number, the average Nusselt number changes are observed at each coolant Prandtl number and heat generation term. Using multiple back-propagation algorithms, the regression analysis of the average 


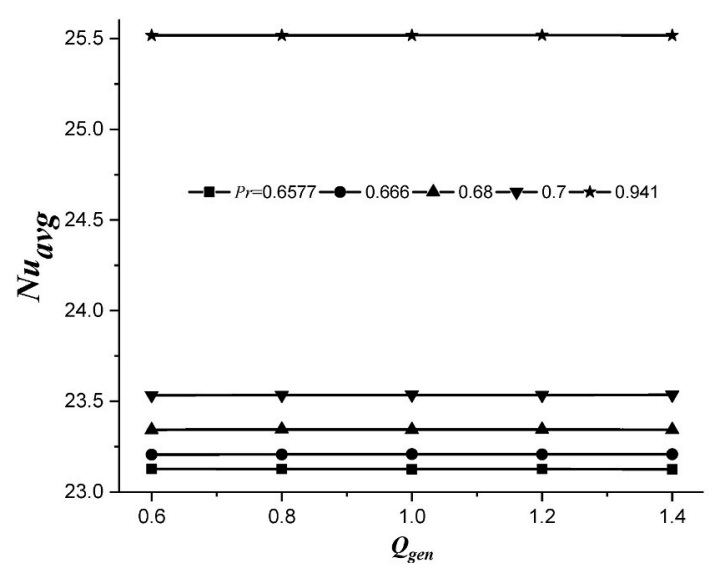

(a) $N u_{a v g}$ for $P r$ of gases with increasing heat generation

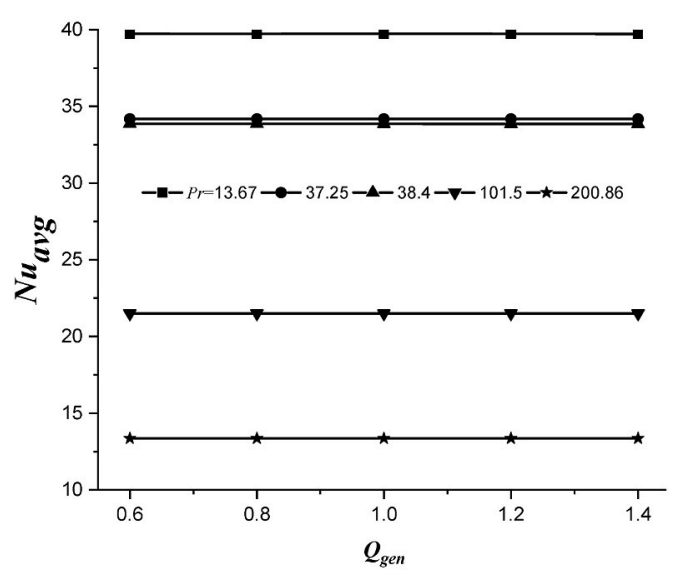

(c) Nuavg for $\mathrm{Pr}$ of thermal oils with increasing heat generation

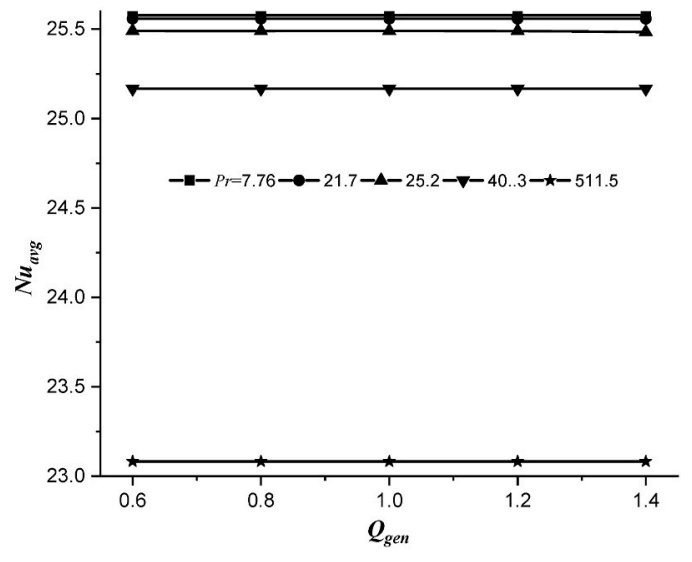

(b) Nuavg for $\mathrm{Pr}$ of oils with increasing heat generation

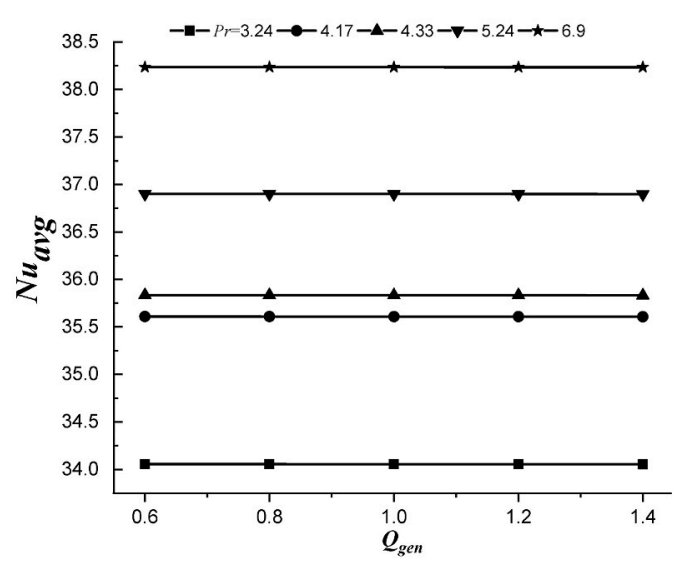

(d) $N u_{a v g}$ for $P r$ of nanofluids with increasing heat generation

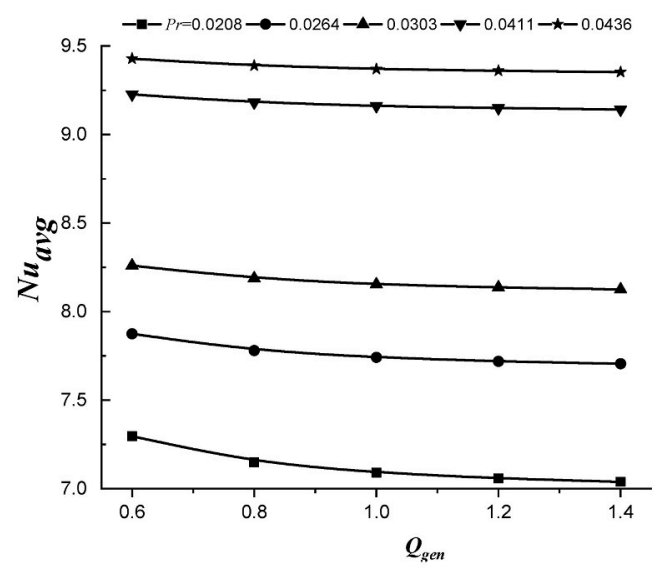

(e) Nuavg for $\operatorname{Pr}$ of liquid metal coolants with increasing heat generation

Fig. 13. $N u_{\text {avg }}$ varying with $\mathrm{Pr}$ of coolants while it remains constant with heat generation.

Nusselt number is performed successfully. The following conclusion is drawn from the detailed analysis.

1. The temperature variations and maximum temperature in the battery pack is found to be strongly influenced by the Reynolds number and conductivity ratio upto certain upper limit.
2. Irrespective of coolants, the total heat generation within the battery pack has very seldom effect on the average Nusselt number.

3. The average Nusselt number exclusively depends on the Prandtl number and Reynolds number. 


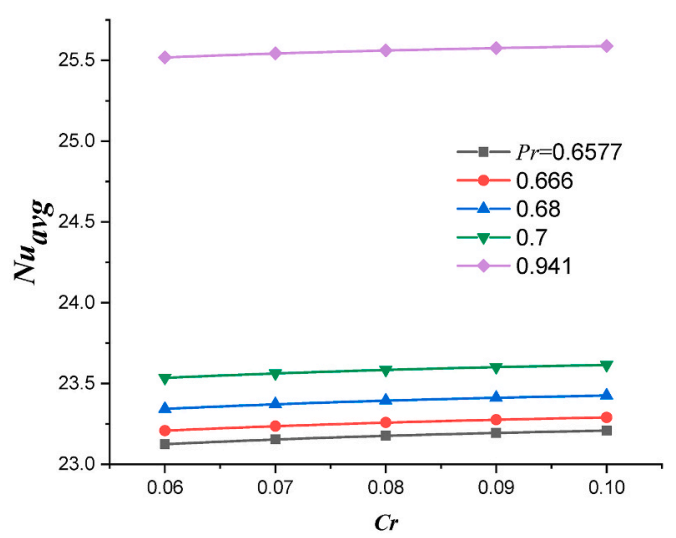

(a) Nuavg for different $\operatorname{Pr}$ of gases with increasing conductivity ratio

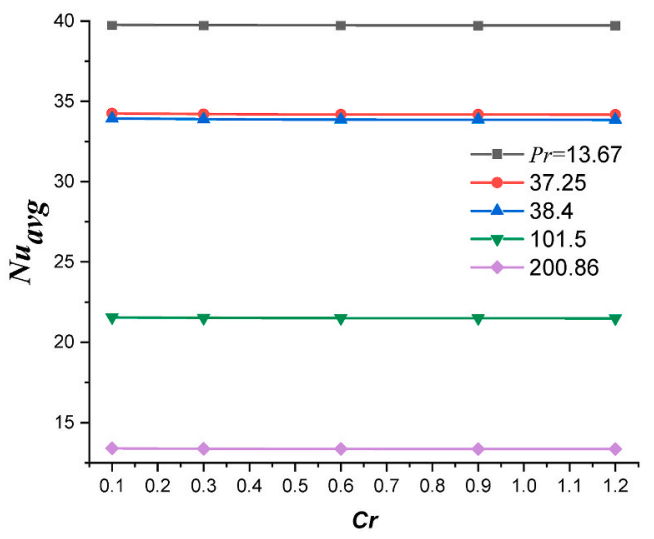

(c) Nuavg for different $\operatorname{Pr}$ of thermal oils with increasing conductivity ratio

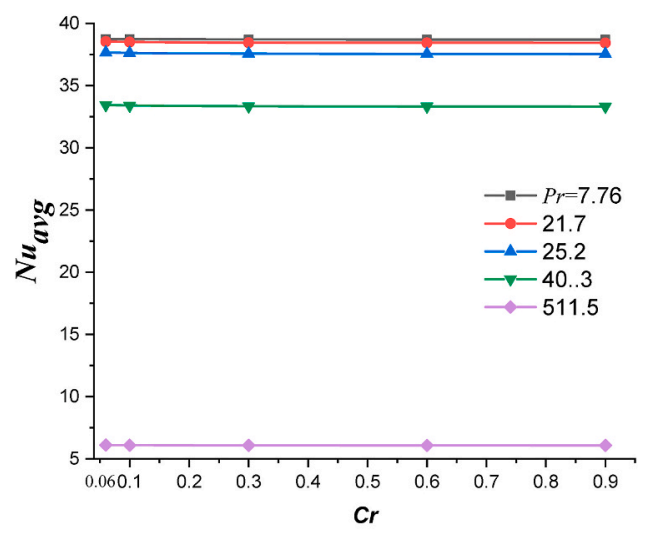

(b) Nuavg for different $\mathrm{Pr}$ of oils with increasing conductivity ratio

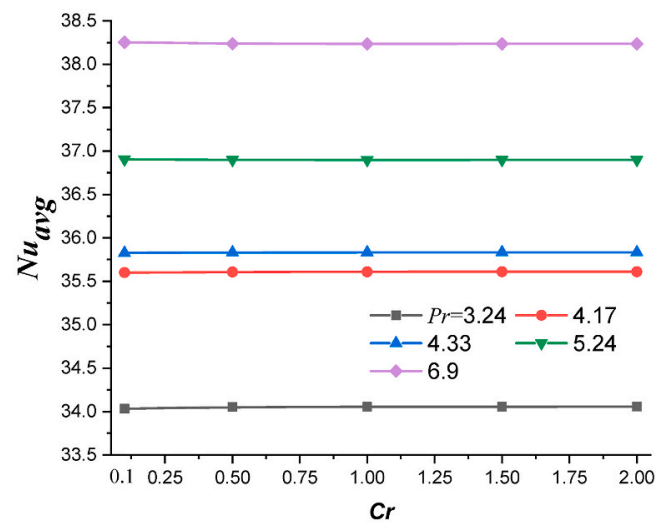

(d) $N u_{a v g}$ for different $P r$ of nanofluids with increasing conductivity ratio

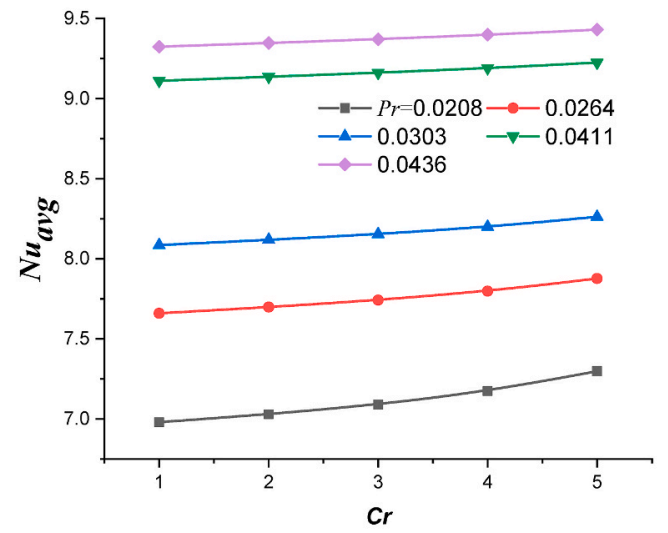

(e) $N u_{\text {avg }}$ for different $\mathrm{Pr}$ of liquid metals with increasing conductivity ratio

Fig. 14. $N u_{a v g}$ varying with $\mathrm{Pr}$ of coolants while it remains constant with conductivity ratio.

4. Nanofluids will be a better choice as a coolant to be used in thermal management of a battery system in terms of heat transfer characteristics and efficient performance.

5. The MBP 1, i.e., feed-forward network with multi-layers, is found to be the best and desirable for average Nusselt number prediction from the training data among the three networks proposed.

6. The space network for battery problems can be suggested as not highly desirable as it consumes computational time. However, CUDA parallel computing tool can be employed for faster training of space networks.

7. The multi-layered feed-forward network with back-propagation with different design complexities or just a simple type can be said to predict the values of average Nusselt number comfortably provided if more training data set can be provided. 


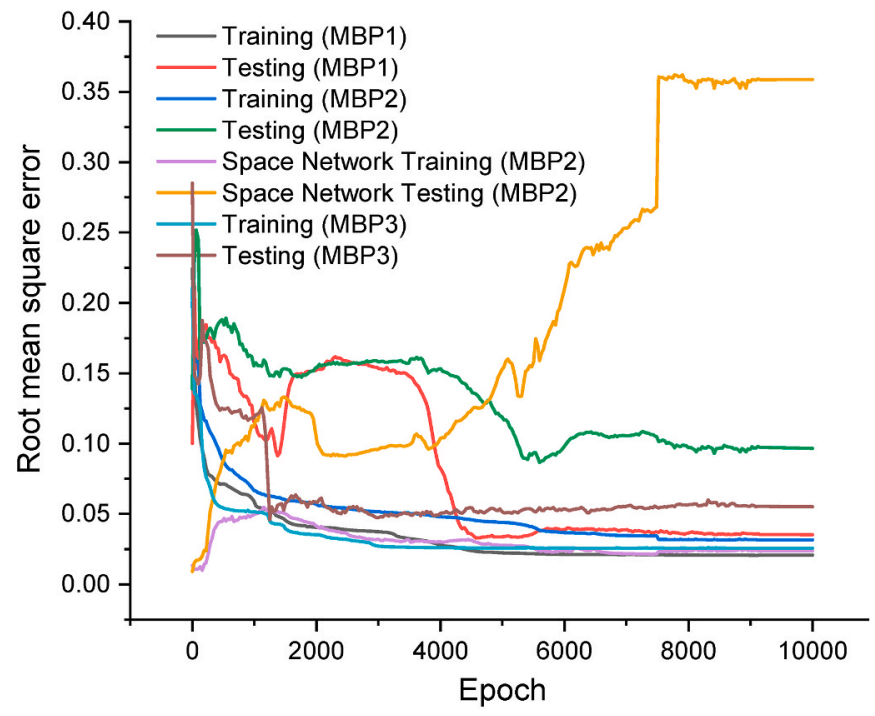

(a) Root mean square error obtained during 10,000 epochs for three proposed MBP models

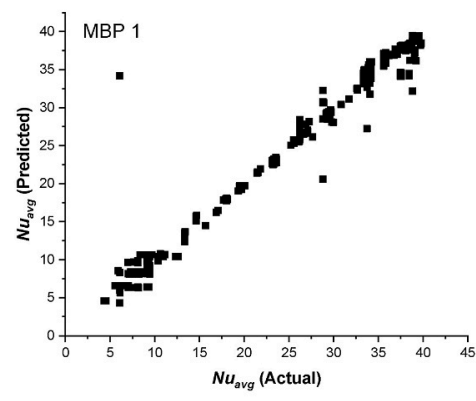

(b) Actual vs predicted by MBP1

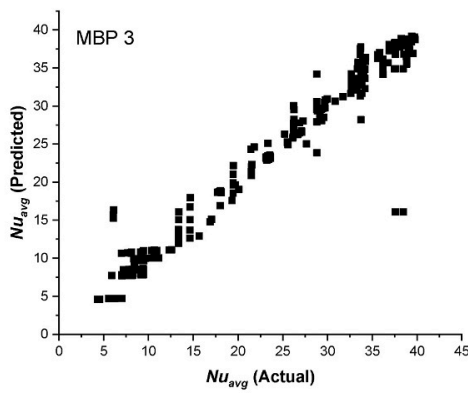

(d) Actual vs. predicted by MBP3

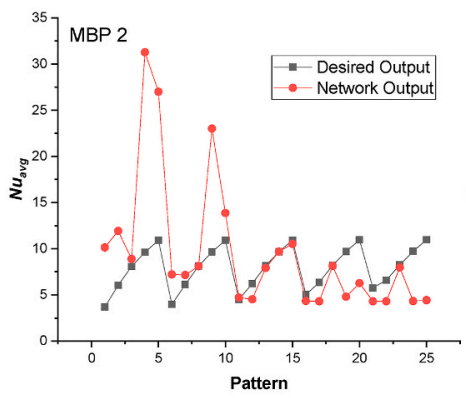

(f) Testing of network output by MBP2

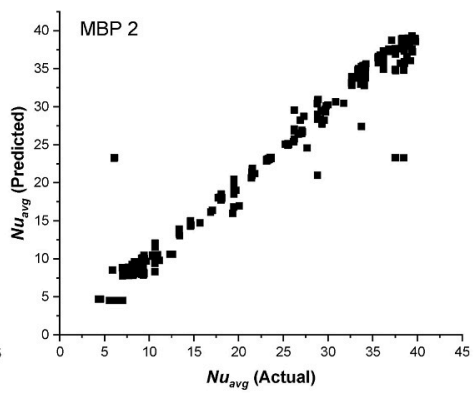

(c) Actual vs predicted by MBP2

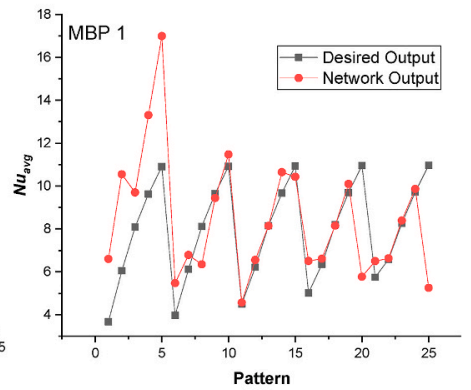

(e) Testing of network output by MBP1

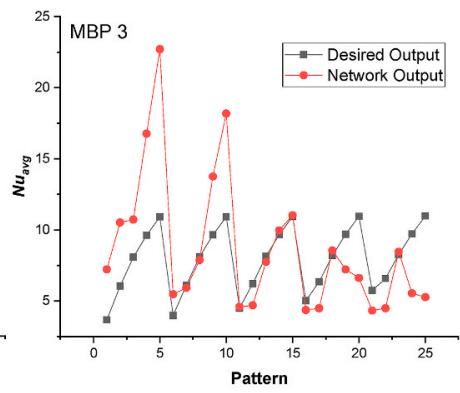

(g) Testing of network output by MBP3

Fig. 15. Results of multiple back-propagation models obtained during the training and testing of three proposed networks. 
Table 2

The weight and Bias function values for MBP 2 network after successful training of the network.

\begin{tabular}{|c|c|c|c|c|c|c|}
\hline \multicolumn{7}{|l|}{ From the input layer } \\
\hline To the 1 st hidden layer & Bias & 1st neuron & 2nd neuron & 3rd neuron & 4th neuron & \\
\hline 1st neuron & 0.588693 & 0.00907816 & 5.93555 & -4.93995 & 6.41379 & \\
\hline 2nd neuron & -6.79518 & 0.0230177 & 1.51154 & -14.4227 & -24.4955 & \\
\hline 3rd neuron & -29.4656 & -0.000482714 & -0.0993503 & -29.0097 & 0.13767 & \\
\hline 4th neuron & -1.4446 & -0.00577124 & -1.70989 & 2.84658 & -0.0416249 & \\
\hline 5th neuron & 8.78692 & 0.00278079 & 1.54161 & 11.9536 & -0.567072 & \\
\hline & \multicolumn{2}{|c|}{ From the 1st hidden layer } & 2nd neuron & 3rd neuron & 4th neuron & 5 th neuron \\
\hline 1st neuron & 1.57239 & -0.0913003 & 11.6817 & -32.628 & -1.34112 & -12.986 \\
\hline 2nd neuron & 3.11951 & -10.327 & -0.746224 & 8.29219 & 4.48886 & -4.35271 \\
\hline 3rd neuron & 0.48561 & -0.652323 & 0.591283 & -0.24702 & -15.2226 & -8.76771 \\
\hline 4th neuron & 11.2404 & 0.204048 & -9.11036 & -13.6569 & -9.81184 & 0.762023 \\
\hline 5th neuron & -14.3203 & -1.42521 & 12.9299 & 10.9794 & 12.8144 & -8.47024 \\
\hline $\begin{array}{l}\text { From the 2nd hidden layer } \\
\text { To the output layer }\end{array}$ & Bias & 1st neuron & 2nd neuron & 3rd neuron & 4th neuron & 5th neuron \\
\hline 1st neuron & 1.16976 & 4.89744 & 1.59646 & 8.37806 & -6.05888 & -12.0827 \\
\hline
\end{tabular}

\section{Declaration of competing interest}

The authors declare they have no conflict of interest.

\section{References}

[1] R. Xiong, H. Chen, C. Wang, F. Sun, Towards a smarter hybrid energy storage system based on battery and ultracapacitor - a critical review on topology and energy management, J. Clean. Prod. 202 (Nov. 2018) 1228-1240, https://doi.org/ 10.1016/J.JCLEPRO. 2018.08.134.

[2] W. Mei, H. Chen, J. Sun, Q. Wang, Numerical study on tab dimension optimization of lithium-ion battery from the thermal safety perspective, Appl. Therm. Eng. 142 (Sep. 2018) 148-165, https://doi.org/10.1016/J. APPLTHERMALENG.2018.06.075.

[3] F. Bai, M. Chen, W. Song, Y. Li, Z. Feng, Y. Li, Thermal performance of pouch Lithium-ion battery module cooled by phase change materials, Energy Procedia 158 (Feb. 2019) 3682-3689, https://doi.org/10.1016/J.EGYPRO.2019.01.891.

[4] S. Ameer, N. Ahamad, Azeem Ahmed, M. Ali Baig, S. Kamangar, I. Anjum Badruddin, Lohith Reddy, Heat transfer in square porous cavity due to radiation and heat generating strip - part i, IOP Conf. Ser. Mater. Sci. Eng. 764 (2020), https://doi.org/10.1088/1757-899X/764/1/012028.

[5] J. Ameer, N. Ahamad, Ahmed Azeem, M. Ali Baig, S. Kamangar, I. Anjum Badruddin, Nagarjun, Heat transfer in square porous cavity due to radiation and heat generating strip - Part II, IOP Conf. Ser. Mater. Sci. Eng. 764 (2020), https:// doi.org/10.1088/1757-899X/764/1/012030.

[6] A. Jarrett, I.Y. Kim, Design optimization of electric vehicle battery cooling plates for thermal performance, J. Power Sources 196 (23) (Dec. 2011) 10359-10368, https://doi.org/10.1016/j.jpowsour.2011.06.090.

[7] P. Peng, F. Jiang, Thermal safety of lithium-ion batteries with various cathode materials: a numerical study, Int. J. Heat Mass Tran. 103 (2016) 1008-1016, https://doi.org/10.1016/j.ijheatmasstransfer.2016.07.088.

[8] J. Kasnatscheew, et al., Lithium ion battery cells under abusive discharge conditions: electrode potential development and interactions between positive and negative electrode, J. Power Sources 362 (2017) 278-282, https://doi.org/ 10.1016/j.jpowsour.2017.07.044.

[9] A. Ali, R. B, M.A.A. Baig, S. Bouadila, Mami, Energy management of a small-scale wind turbine system combined with battery storage system, Int. J. Mech. Prod. Eng. Res. Dev. 8 (3) (2018) 1167-1178, https://doi.org/10.24247/ijmperdjun2018121.

[10] S. Wang, K. Li, Y. Tian, J. Wang, Y. Wu, S. Ji, Improved thermal performance of a large laminated lithium-ion power battery by reciprocating air flow, Appl. Therm. Eng. (2019), https://doi.org/10.1016/j.applthermaleng.2019.02.061.

[11] T. Wang, K. Tseng, J. Zhao, Z. Wei, Thermal investigation of lithium-ion battery module with different cell arrangement structures and forced air-cooling strategies, Appl. Energy 134 (2014) 229-238. https://www.sciencedirect.com/science/artic le/pii/S0306261914008162.

[12] X. Na, H. Kang, T. Wang, Y. Wang, Reverse layered air flow for Li-ion battery thermal management, Appl. Therm. Eng. 143 (2018) 257-262, https://doi.org/ 10.1016/j.applthermaleng.2018.07.080.

[13] Z. Lu, et al., Parametric study of forced air cooling strategy for lithium-ion battery pack with staggered arrangement, Appl. Therm. Eng. (2018), https://doi.org/ 10.1016/j.applthermaleng.2018.02.080.

[14] L. Fan, J. Khodadadi, A.A. Pesaran, A parametric study on thermal management of an air-cooled lithium-ion battery module for plug-in hybrid electric vehicles, J. Power Sources 238 (2013) 301-312. https://www.sciencedirect.com/science/ article/pii/S0378775313004412.
[15] M.R. Giuliano, A.K. Prasad, S.G. Advani, Experimental study of an air-cooled thermal management system for high capacity lithium-titanate batteries, J. Power Sources (2012), https://doi.org/10.1016/j.jpowsour.2012.05.074.

[16] C. Zhu, X. Li, L. Song, L. Xiang, Development of a theoretically based thermal model for lithium ion battery pack, J. Power Sources (2013), https://doi.org/ 10.1016/j.jpowsour.2012.09.035.

[17] L.H. Saw, Y. Ye, A.A.O. Tay, W.T. Chong, S.H. Kuan, M.C. Yew, Computational fluid dynamic and thermal analysis of Lithium-ion battery pack with air cooling, Appl. Energy 177 (2016) 783-792, https://doi.org/10.1016/j. apenergy.2016.05.122.

[18] K. Chen, Y. Chen, Y. She, M. Song, S. Wang, L. Chen, Construction of effective symmetrical air-cooled system for battery thermal management, Appl. Therm. Eng. 166 (Feb. 2020) 114679, https://doi.org/10.1016/j.applthermaleng.2019.114679.

[19] J. Zhang, H. Kang, K. Wu, J. Li, Y. Wang, The impact of enclosure and boundary conditions with a wedge-shaped path and air cooling for battery thermal management in electric vehicles, Int. J. Energy Res. 42 (13) (Oct. 2018) 4054-4069, https://doi.org/10.1002/er.4122.

[20] X. Peng, C. Ma, A. Garg, N. Bao, X. Liao, Thermal performance investigation of an air-cooled lithium-ion battery pack considering the inconsistency of battery cells, Appl. Therm. Eng. 153 (May 2019) 596-603, https://doi.org/10.1016/j. applthermaleng.2019.03.042.

[21] S. Shahid, M. Agelin-Chaab, Experimental and numerical studies on air cooling and temperature uniformity in a battery pack, Int. J. Energy Res. 42 (6) (May 2018) 2246-2262, https://doi.org/10.1002/er.4018.

[22] S. Panchal, I. Dincer, Agelin-Chaab, R. Fraser, M. Fowler, Experimental and theoretical investigations of heat generation rates for a water cooled LiFePO4 battery, Int. J. Heat Mass Tran. 101 (2016) 1093-1102 [Online]. Available: https://www.sciencedirect.com/science/article/pii/S0017931016302034. (Accessed 23 May 2018).

[23] S. Panchal, I. Dincer, M. Agelin-Chaab, R. Fraser, M. Fowler, Experimental investigation and simulation of temperature distributions in a 16Ah-LiMnNiCoO 2 battery during rapid discharge rates, Heat Mass Tran. 53 (3) (2017) 937-946.

[24] J. Smith, R. Singh, M. Hinterberger, M. Mochizuki, Battery thermal management system for electric vehicle using heat pipes, Int. J. Therm. Sci. 134 (2018) 517-529, https://doi.org/10.1016/j.ijthermalsci.2018.08.022.

[25] J. Cen, Z. Li, F. Jiang, Experimental investigation on using the electric vehicle air conditioning system for lithium-ion battery thermal management, Energy Sustain. Dev. 45 (2018) 88-95, https://doi.org/10.1016/j.esd.2018.05.005.

[26] X. Zhang, C. Liu, Z. Rao, Experimental investigation on thermal management performance of electric vehicle power battery using composite phase change material, J. Clean. Prod. 201 (2018) 916-924, https://doi.org/10.1016/j. jclepro.2018.08.076.

[27] Z. Liu, Y. Wang, J. Zhang, Z. Liu, Shortcut computation for the thermal management of a large air-cooled battery pack, Appl. Therm. Eng. (2014), https:// doi.org/10.1016/j.applthermaleng.2014.02.040.

[28] K. Li, J. Yan, H. Chen, Q. Wang, Water cooling based strategy for lithium ion battery pack dynamic cycling for thermal management system, Appl. Therm. Eng. 132 (2018) 575-585, https://doi.org/10.1016/j.applthermaleng.2017.12.131.

[29] D. Chen, J. Jiang, G.H. Kim, C. Yang, A. Pesaran, Comparison of different cooling methods for lithium ion battery cells, Appl. Therm. Eng. 94 (2016) 846-854, https://doi.org/10.1016/j.applthermaleng.2015.10.015.

[30] Z. Qian, Y. Li, Z. Rao, Thermal performance of lithium-ion battery thermal management system by using mini-channel cooling, Energy Convers. Manag. 126 (2016) 622-631, https://doi.org/10.1016/j.enconman.2016.08.063.

[31] D. Chalise, K. Shah, R. Prasher, A. Jain, Conjugate heat transfer analysis of air/ liquid cooling of a Li-ion battery pack, J. Electrochem. Energy Convers. Storage 15 (2018) 1-8, https://doi.org/10.1115/1.4038258, 011008. 
[32] G. Xia, L. Cao, G. Bi, A review on battery thermal management in electric vehicle application, J. Power Sources 367 (2017) 90-105, https://doi.org/10.1016/j. jpowsour.2017.09.046.

[33] J. He, X. Yang, G. Zhang, A phase change material with enhanced thermal conductivity and secondary heat dissipation capability by introducing a binary thermal conductive skeleton for battery thermal management, Appl. Therm. Eng. 148 (2019) 984-991, https://doi.org/10.1016/j.applthermaleng.2018.11.100.

[34] Y. Lv, W. Situ, X. Yang, G. Zhang, Z. Wang, A novel nanosilica-enhanced phase change material with anti-leakage and anti-volume-changes properties for battery thermal management, Energy Convers. Manag. 163 (2018) 250-259, https://doi. org/10.1016/j.enconman.2018.02.061.

[35] W. Situ, et al., A thermal management system for rectangular LiFePO4 battery module using novel double copper mesh-enhanced phase change material plates, Energy 141 (2017) 613-623, https://doi.org/10.1016/j.energy.2017.09.083.

[36] Y. Xie, et al., Experimental and numerical investigation on integrated thermal management for lithium-ion battery pack with composite phase change materials, Energy Convers. Manag. 154 (October) (2017) 562-575, https://doi.org/10.1016/ j.enconman.2017.11.046.

[37] A. Afzal, A.D.M. Samee, R.K.A. Razak, M.K. Ramis, Steady and transient state analyses on conjugate laminar forced convection heat transfer, Arch. Comput. Methods Eng. 27 (2020) 135-170, https://doi.org/10.1007/s11831-018-09303-x.

[38] H. Maleki, S. Al Hallaj, J.R. Selman, R.B. Dinwiddie, H. Wang, Thermal propertie of lithium-ion battery and components, J. Electrochem. Soc. 146 (3) (1999) 947-954.

[39] D. Werner, A. Loges, D.J. Becker, T. Wetzel, Thermal conductivity of Li-ion batteries and their electrode configurations - a novel combination of modelling and experimental approach, J. Power Sources 364 (2017) 72-83, https://doi.org/ 10.1016/j.jpowsour.2017.07.105.

[40] D. Chalise, K. Shah, R. Prasher, A. Jain, Conjugate heat transfer analysis of therma management of a Li-ion battery pack, J. Electrochem. Energy Convers. Storage 15 (1) (2018) 11008

[41] I. Dincer, H.S. Hamut, N. Javani, Thermal Management of Electric Vehicle Battery Systems, John Wiley \& Sons, 2016.

[42] F. Richter, P.J.S. Vie, S. Kjelstrup, O.S. Burheim, Measurements of ageing and thermal conductivity in a secondary NMC-hard carbon Li-ion battery and the impact on internal temperature profiles, Electrochim. Acta 250 (2017) 228-237, https://doi.org/10.1016/j.electacta.2017.07.173.

[43] R. Kantharaj, A.M. Marconnet, Heat generation and thermal transport in lithiumion batteries: a scale-bridging perspective, Nanoscale Microscale Thermophys. Eng. 23 (2) (2019) 128-156.

[44] S. Panchal, I. Dincer, M. Agelin-Chaab, R. Fraser, M. Fowler, Thermal modeling and validation of temperature distributions in a prismatic lithium-ion battery at different discharge rates and varying boundary conditions, Appl. Therm. Eng. 96 (2016) 190-199, https://doi.org/10.1016/j.applthermaleng.2015.11.019.

[45] B. Dawoud, E. Amer, D. Gross, Experimental investigation of an adsorptive thermal energy storage, Int. J. Energy Res. 31 (2) (2007) 135-147.

[46] X.M. Xu, R. He, Research on the heat dissipation performance of battery pack based on forced air cooling, J. Power Sources 240 (2013) 33-41, https://doi.org/ 10.1016/j.jpowsour.2013.03.004.

[47] A. Bejan, Convection Heat Transfer, John wiley \& sons, 2013.

[48] A. Afzal, A.D.M. Samee, R.K.A. Razak, M.K. Ramis, Thermal management of modern electric vehicle battery systems (MEVBS), J. Therm. Anal. Calorim. (2020) 1-17, https://doi.org/10.1007/s10973-020-09606-x.

[49] I. Mokashi, S. Afghan, A. Nur, Abdullah, B. Hanafi, Muhammad Azami, A. Afzal, "Maximum temperature analysis in a $\mathrm{Li}$ - ion battery pack cooled by different fluids, J. Therm. Anal. Calorim. (2020) 1-17, https://doi.org/10.1007/s10973020-10063-9.

[50] A. Afzal, A.D. Mohammed Samee, R.K. Abdul Razak, M.K. Ramis, Effect of spacing on thermal performance characteristics of Li-ion battery cells, J. Therm. Anal. Calorim. 135 (3) (2019) 1797-1811, https://doi.org/10.1007/s10973-018-7664

[51] F. Richter, S. Kjelstrup, P.J.S. Vie, O.S. Burheim, Thermal conductivity and internal temperature profiles of Li-ion secondary batteries, J. Power Sources 359 (2017) 592-600, https://doi.org/10.1016/j.jpowsour.2017.05.045.

[52] A. Afzal, et al., "Human thermal comfort in passenger vehicles using an organic phase change material- an experimental investigation, neural network modelling, and optimization, Build. Environ. 180 (April) (2020) 107012, https://doi.org/ 10.1016/j.buildenv.2020.107012.

[53] A.I. khalil Alsmadi M, K.B. Omar, S.A. Noah, Performance comparison of multilayer perceptron (Back Propagation, Delta Rule and Perceptron) algorithms in neural networks, in: IEEE International Advance Computing Conference, 2009, pp. 296-299.

[54] A. Afzal, I. Nawfal, I.M. Mahbubul, S.S. Kumbar, An overview on the effect of ultrasonication duration on different properties of nanofluids, J. Therm. Anal. Calorim. 135 (2019) 393-418, https://doi.org/10.1007/s10973-018-7144-8.

[55] Asif Afzal, S.A. Khan, C.A. Salee, Role of ultrasonication duration and surfactant on characteristics of $\mathrm{ZnO}$ and $\mathrm{CuO}$ nanofluids, Mater. Res. Express 6 (11) (2019) 1150d8, https://doi.org/10.1088/2053-1591/ab5013.

[56] A. Afzal, M.S. Ad, A.R. Rk, Experimental thermal investigation of CuO-W nanofluid in circular minichannel, Model. Meas. Control B 86 (2) (2017) 335-344.

[57] A. Afzal, A.D.M. Samee, R.K.A. Razak, Comparative thermal performance analysis of water, engine coolant oil and MWCNT-W nanofluid in a radiator, Model. Meas. Control B 87 (1) (2018) 1-6. 